\title{
إدارة مرحلة الصيانة للفراغات الخارجية بالمجتمعات العمرانية المغلقة (مدخل لتحقيق الإستدامة الإدارية )

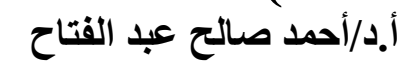

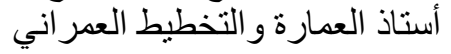 \\ قسم الهندسة المعمارية \\ كلية الهندسة بالمطرية-جامعة حلوان \\ أ.د/داليا وجيه عبد الحليم \\ أستاذ العمارة والتنسيق الحضري الحلمي \\ قسم الهندسة المعمارية \\ كلية الهندسة بالمطرية-جامعة حلوانة \\ ولاء محمد \\ مهندسة معمارية
}

مقدمة

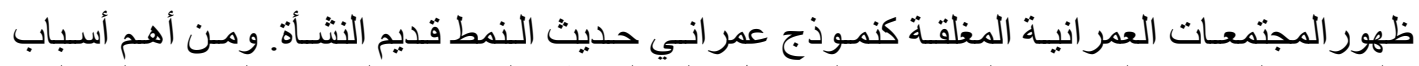

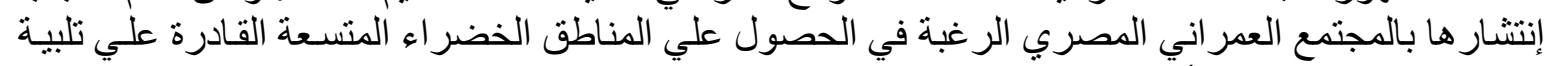

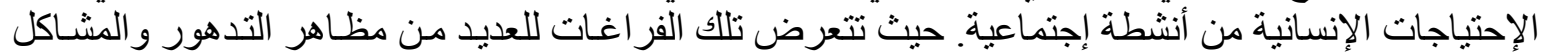

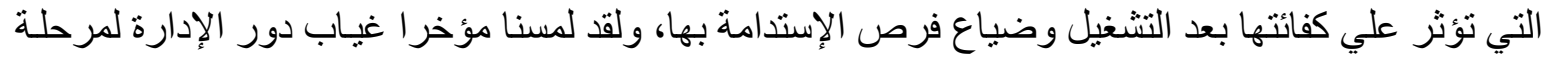

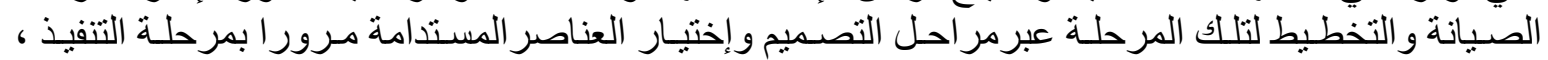

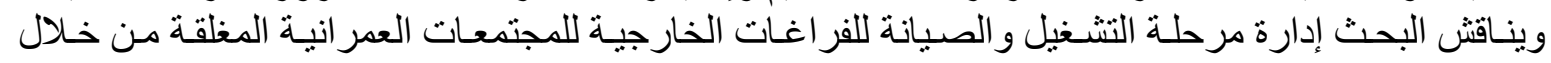

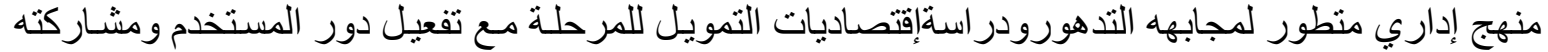

في تحديث فو اعد البيانات، بالإضافة الي إستخدام التطبيقات التكنولوجية الحديثة داخل المنظومة الإدارية.

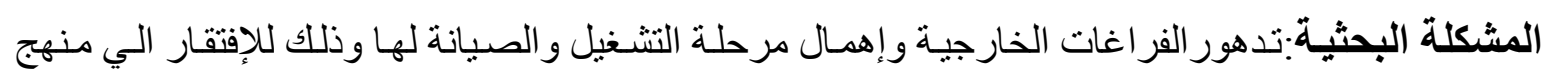

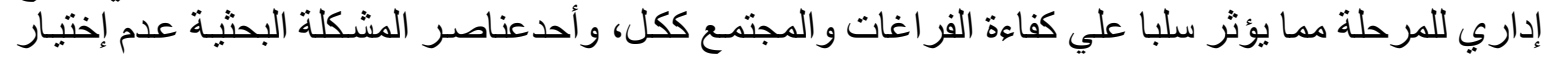

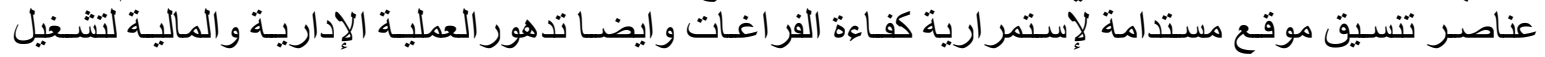
المرحلة.

هدف الاراسة: حيث يهدف البحث الي إستنباط نموذج إداري لمرحلة التشغيل و الصيانة من خـلال تدقيق عدة

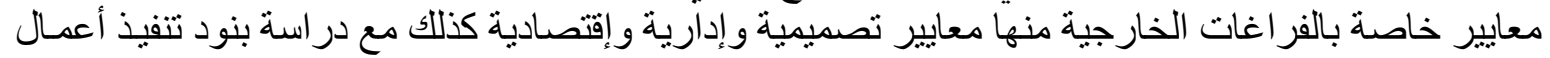

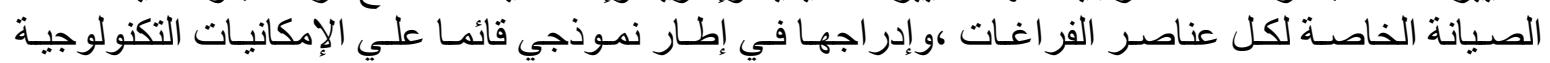

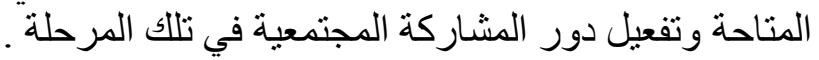

منهج البحث المتبع:منهج وصفي تحليلي حيث التركيز علي الدراسات السابقة وتحليلها والإستفادة منها. الخطة البحثية: يتبع البحث خطة الدراسة للوصول الي تحقيق أهداف البحث التي تقوم عليها الدر اسـة ليحتوي

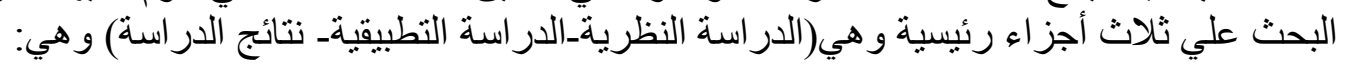

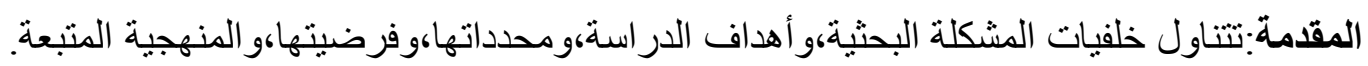


أولا الاراسة النظرية:تتناول الأتي:

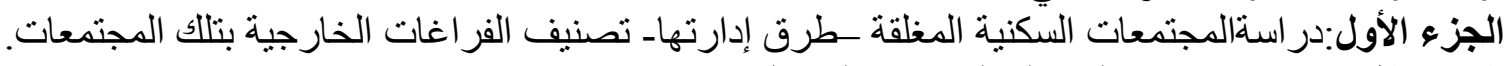

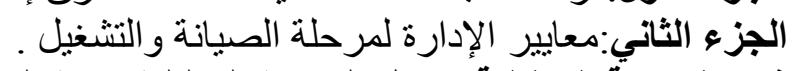

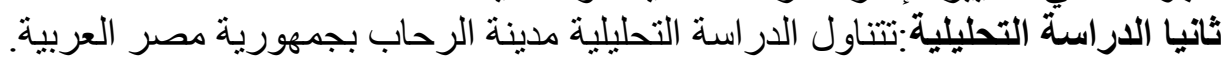

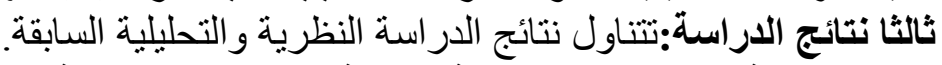

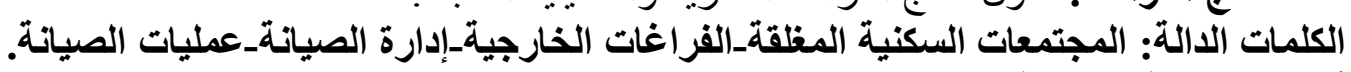

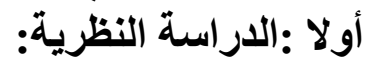

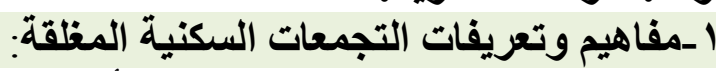

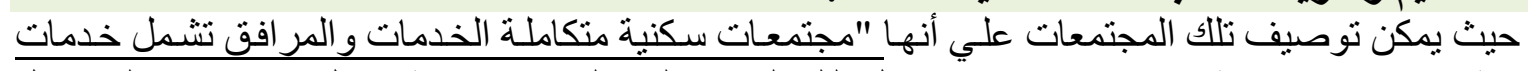

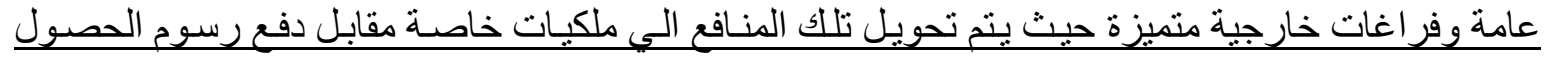

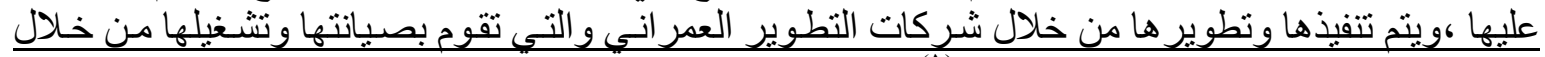

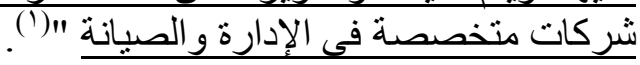
ويتلخص توصيف المجتمعات السكنية المغلقة في الثكل (1) (1):

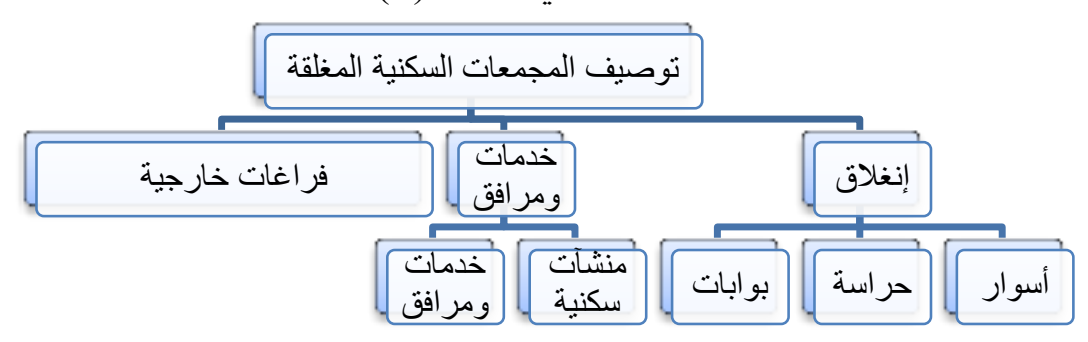

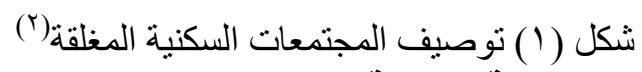

أـ أهم أسباب ظهور المجتمعات السكنية المغلقة :

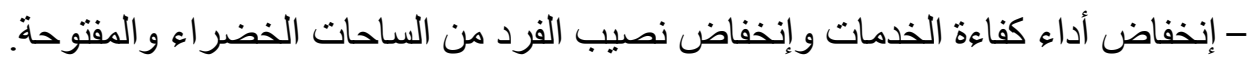

- الرغبة في إسلوب حياة مميزوزيادة معدلات الرفاهية عن المجتمعات التقليدية.

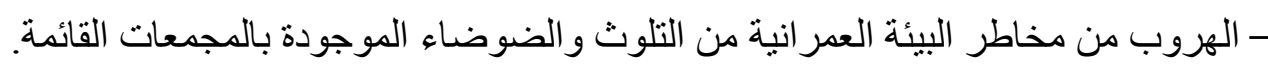
- إعتبار ها حلا للمشاكل الفعلية في المناطق الحضرية ومن الإزدحام وعدم الإحساس بلأل بالامان.

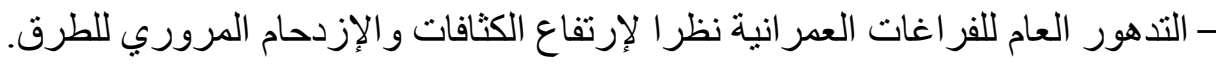

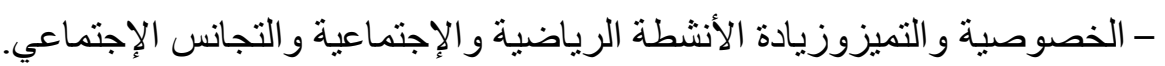

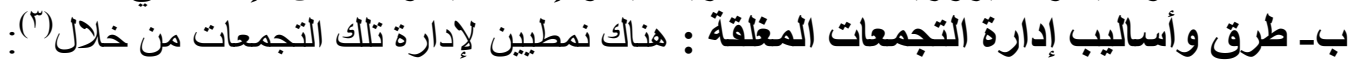

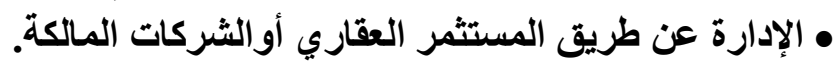

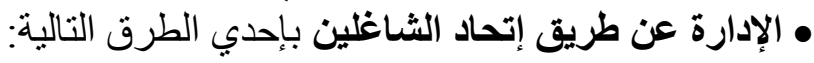

$$
\text { - تعبين مديرين. }
$$

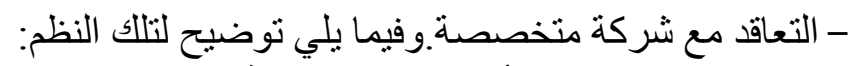

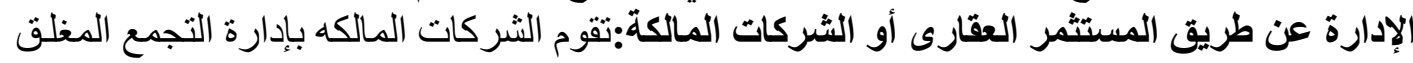

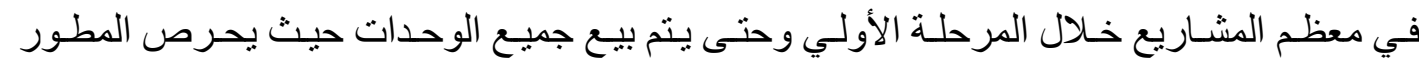

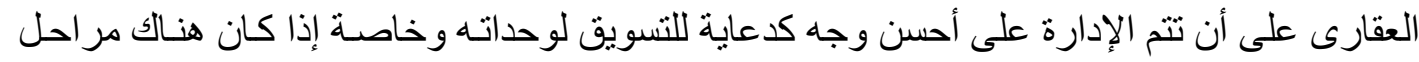

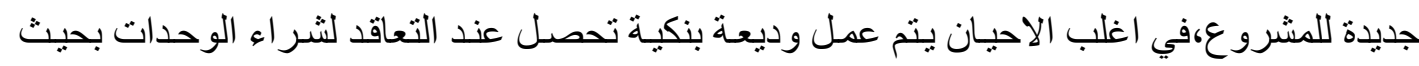

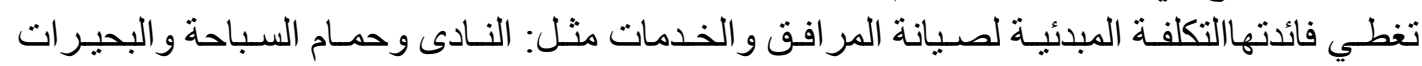

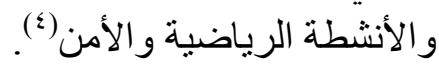




\section{الإدارة عن طريق إتحاد الشاغلين:}

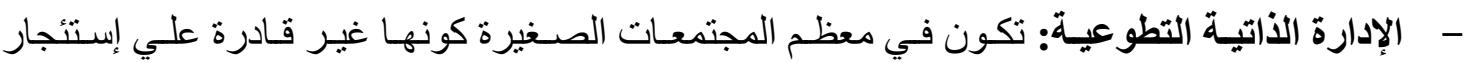

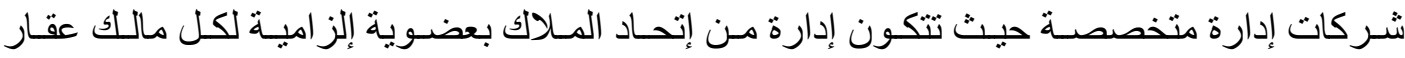

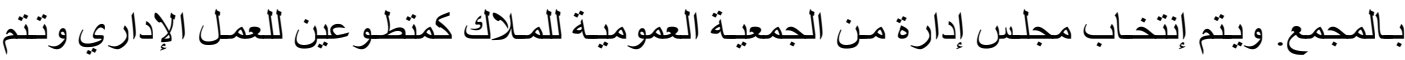

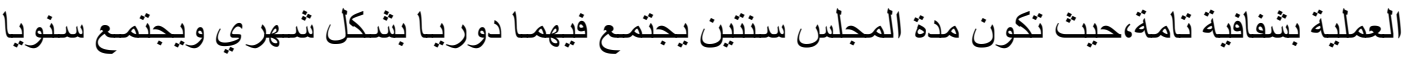

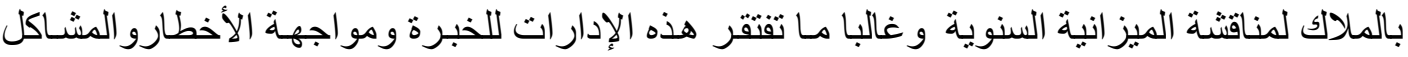
مما يؤثر علي العملية التشغيلية ومرحلة الصيانة (0).

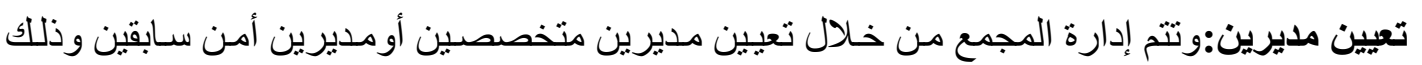

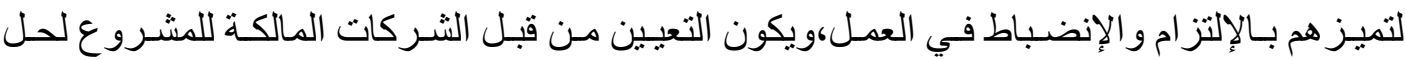
المشكلات مع إتحاد الملاك. - التعاقد مـع شـركات متخصصـة:تتعاقد شـركات التطوير العقاري مـع شـركات متخصصــة في كافـة

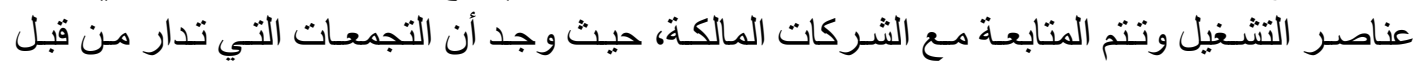

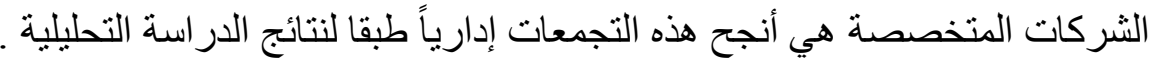

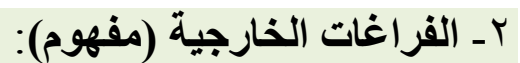

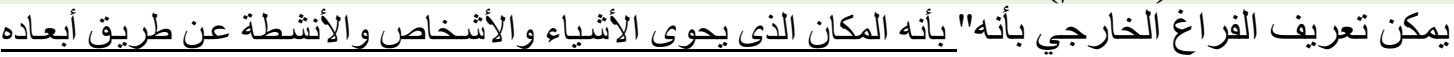

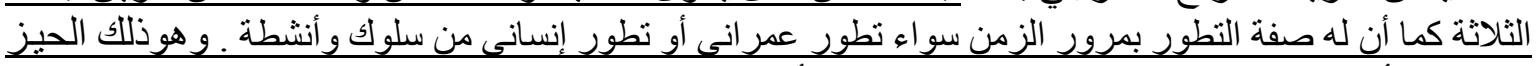

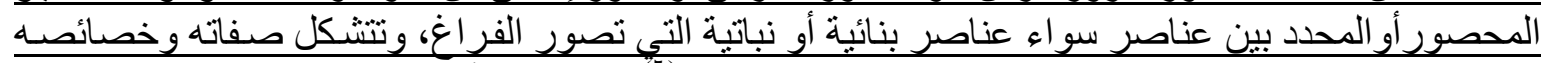

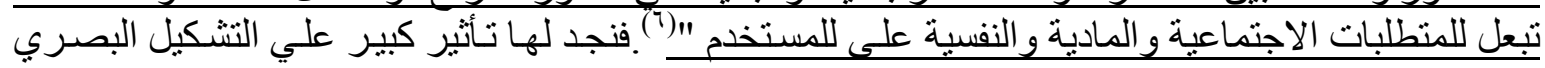

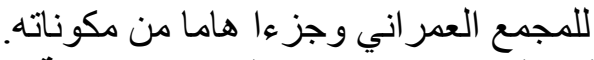

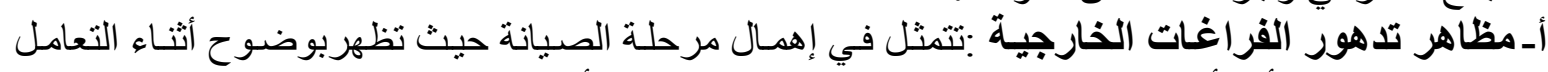

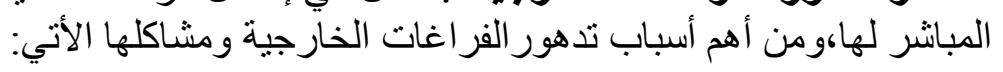

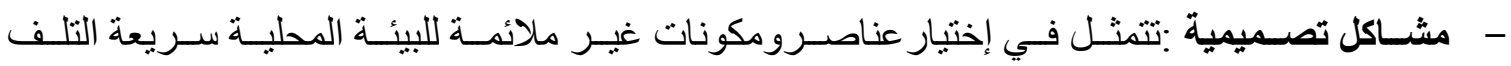

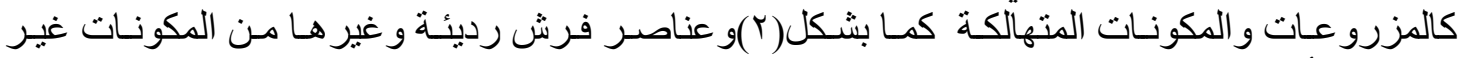

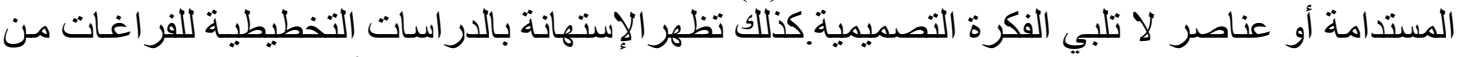

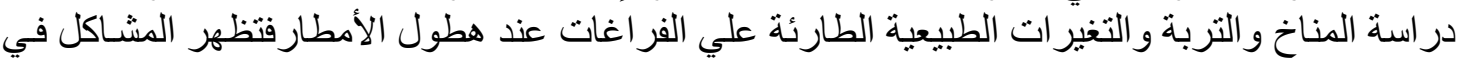

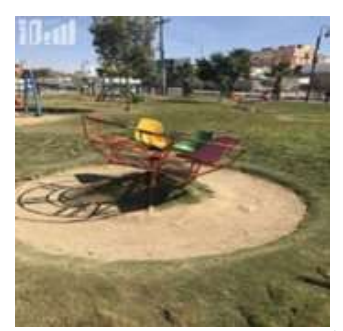
نظم الصرف و غير هاو بالتالي عدم كفاءة الحلول التيرل التصميمية التهية

شكل (ץ) مظاهر لسوء إختيار العناصرداخل الفراغات

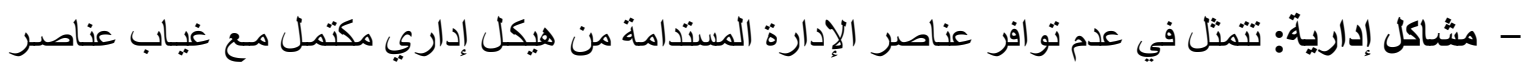

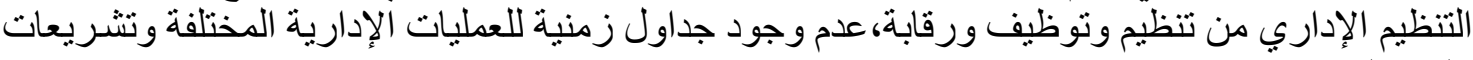
ملزمة لتنفيذها.

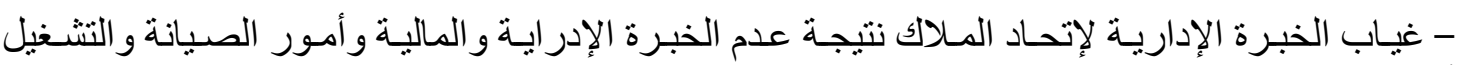
أو التعاقد مع مديرين ليس لايهم خبرة كافية.

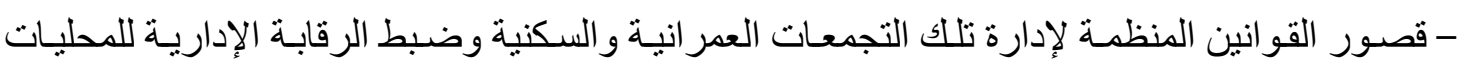

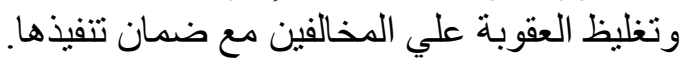




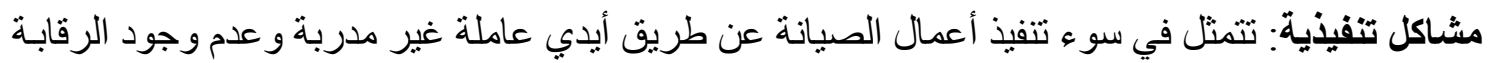

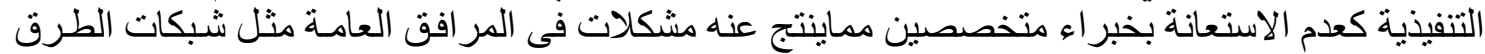

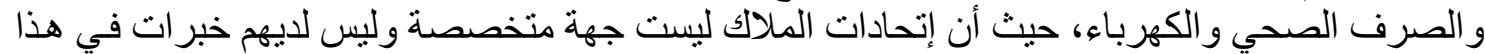

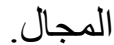

مشاكل إقتصادية: وتتمثل في عدم توافر التمويل الازم لعملية الصيانة من عدم ربطوديعة بنكية من البداية

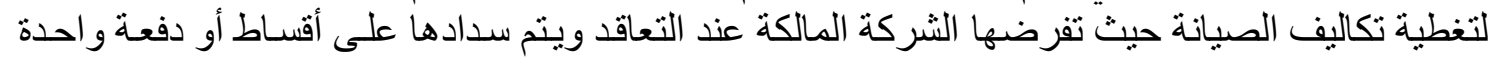

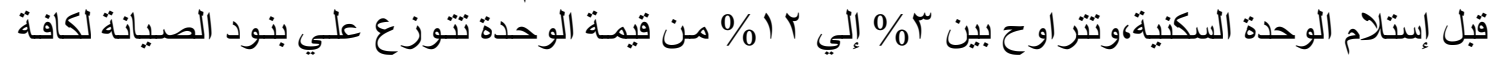

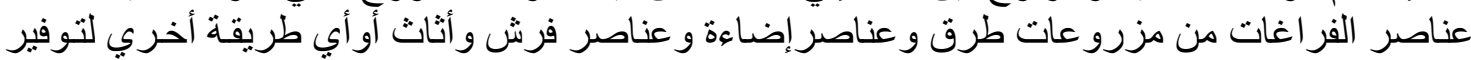

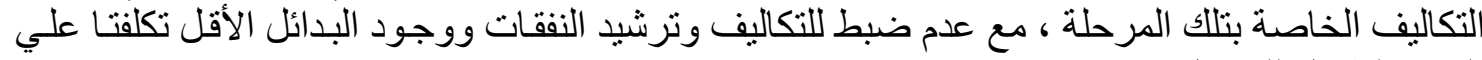

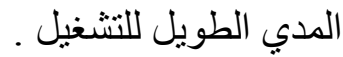

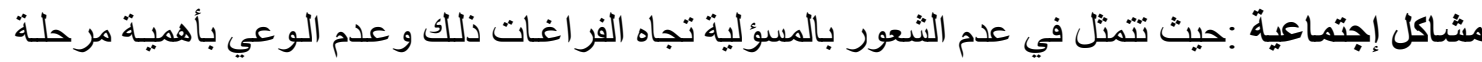

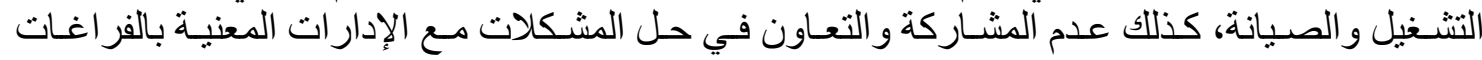

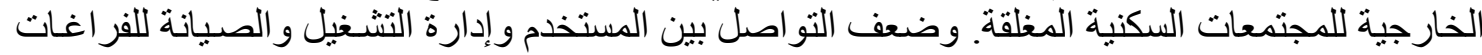

ب-يمكن تلخيص أسباب تدهور الفراغات الخارجية والتعرف علي مظاهره من خلال الثكل (ب):

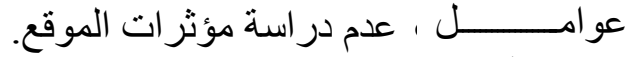

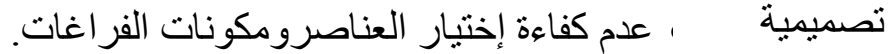

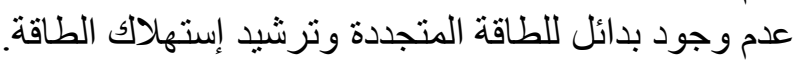

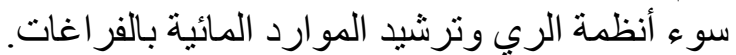

عدم كفاءة نظم جمع وتدوير المخلفات.

عو امل إدارية ، مستوى جوده الإشر اف و العمالة(فرق العمل) القائمة على التنفيذ. بسبب سوء التنفيذ أومخالفه التصميم.

عدم وجود هيكل إداري مكتمل.

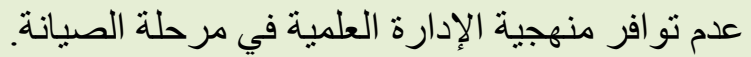

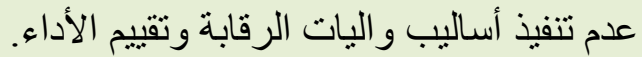

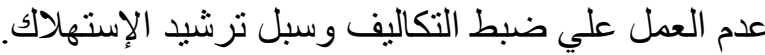

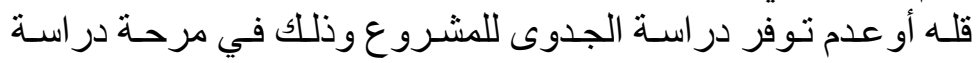

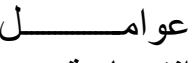

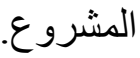

اقتصادية

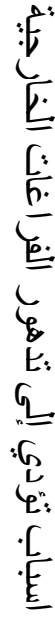

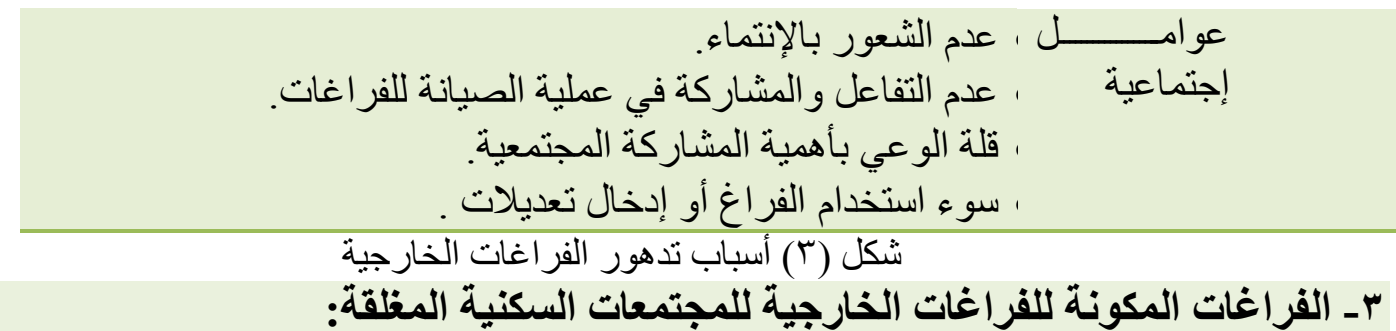

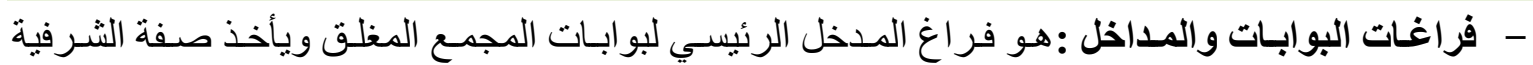

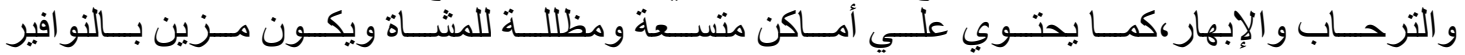

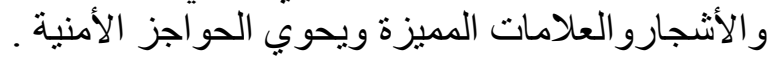

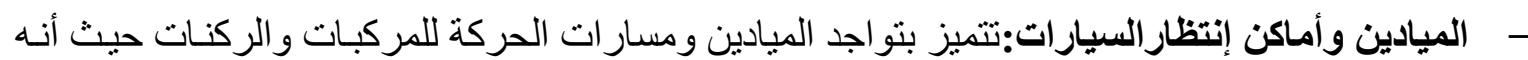

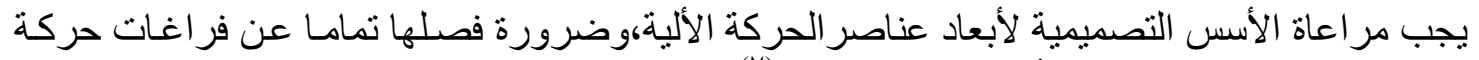

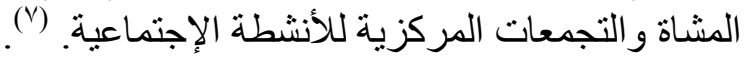

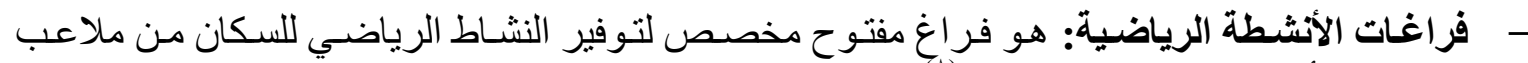

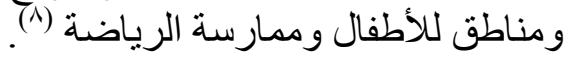




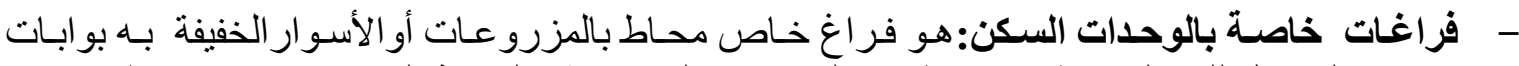

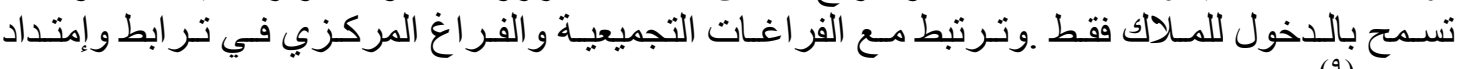

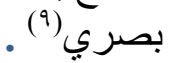
- فراغ تجميعي للمجموعة السكنية : هو فر اغ شبة خاص ذو مقياس إنساني ودرجة إحتو اء متوسطة بحيث

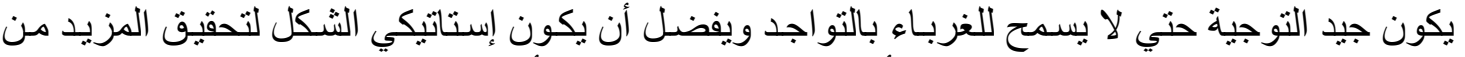

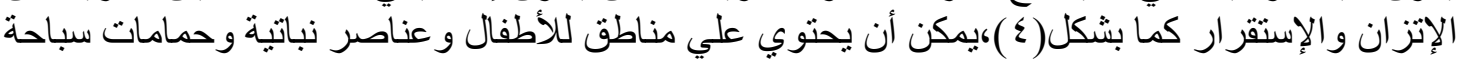
لزيادة الكفاءة الجماليةو الوظيفية.

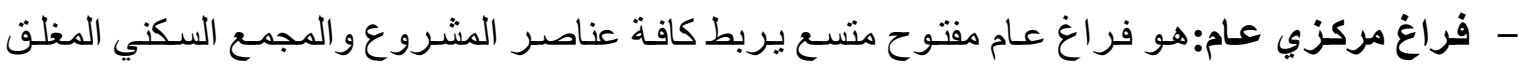

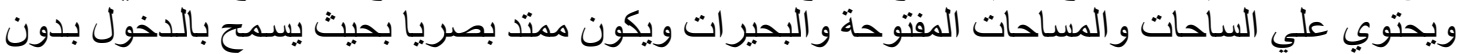

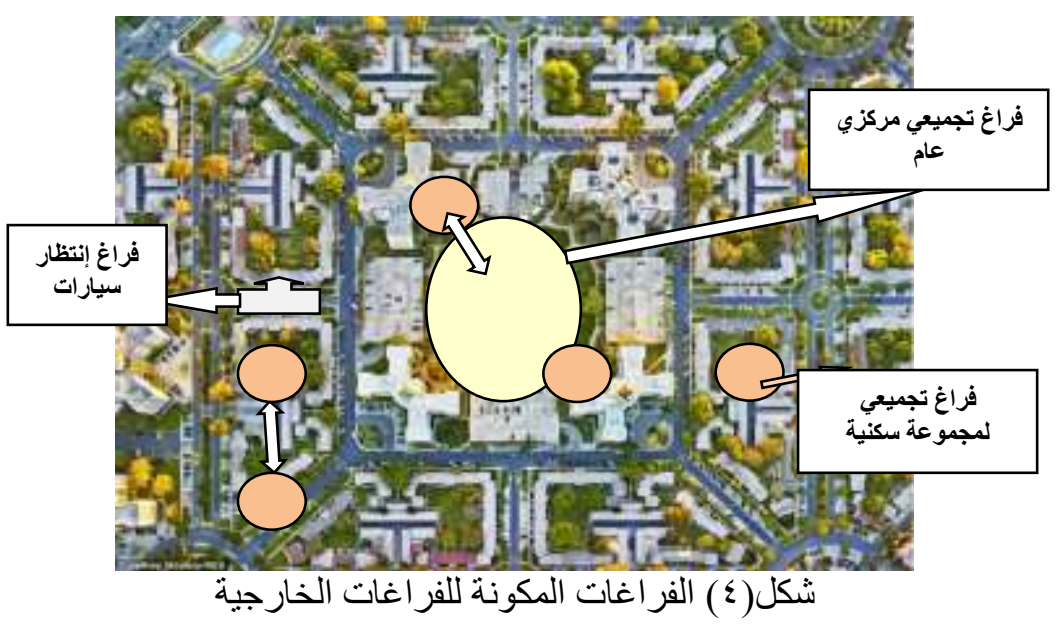

( ) معايير الإدارة لمرحلة تشغيل صيانة الفراغات الخارجية

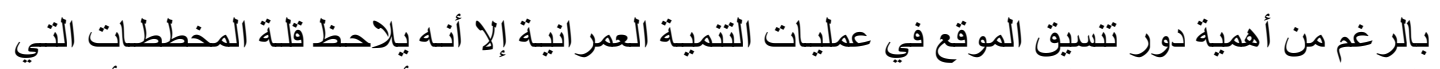

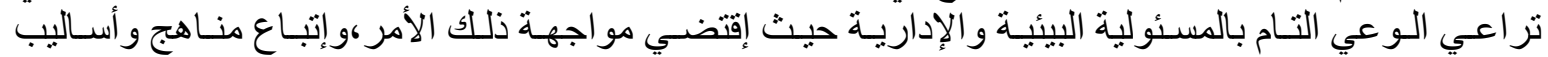

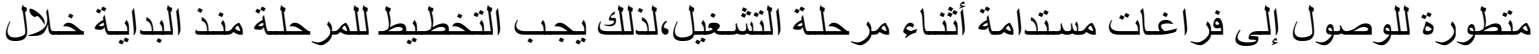

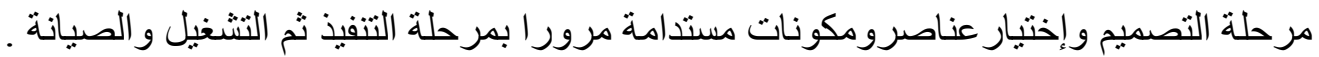

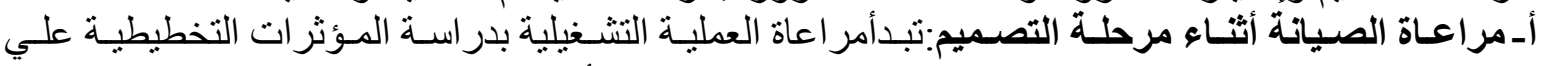

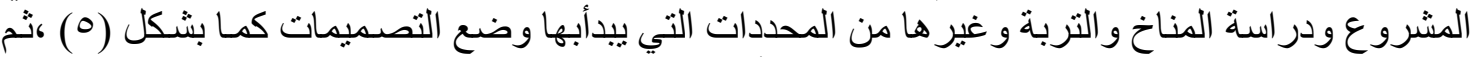

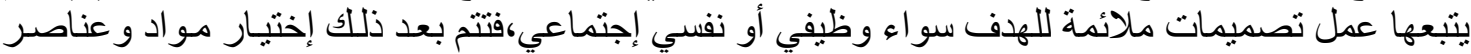

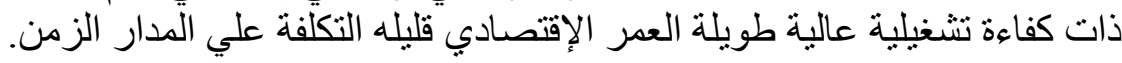
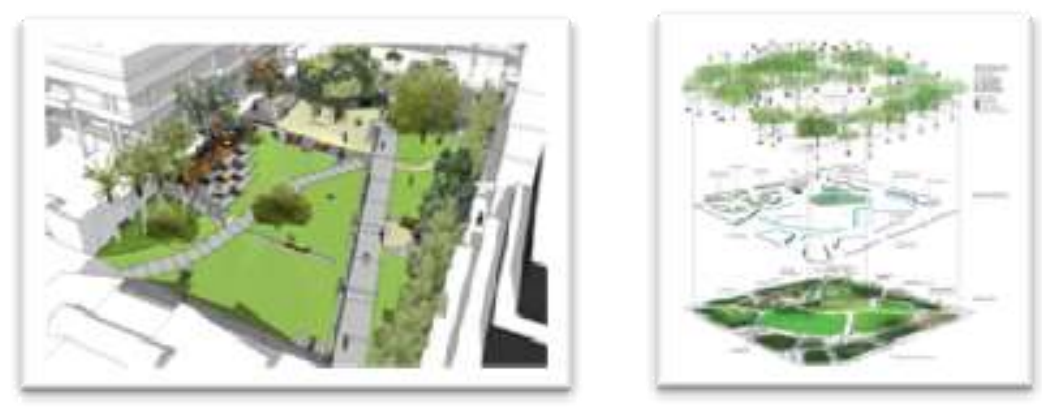

شكل (0) الدراسات التخطيطية والتصميمية لمرحلة تصميم الفراغات 


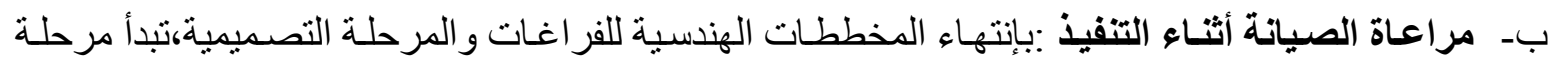

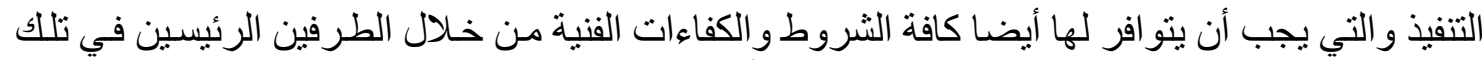

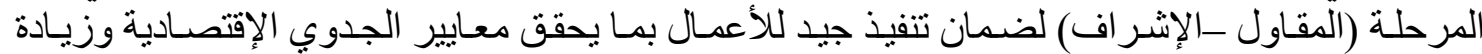

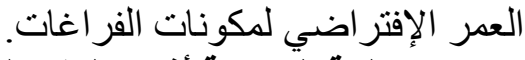

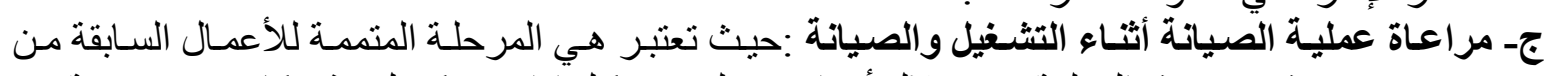

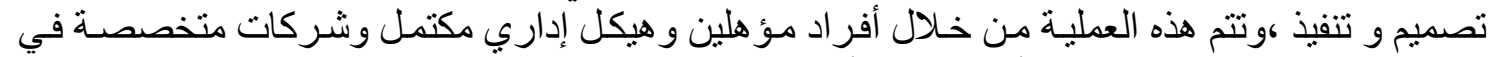

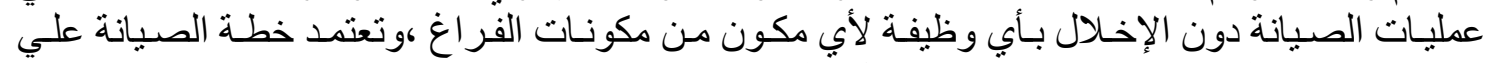

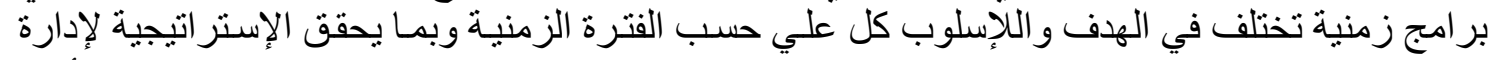

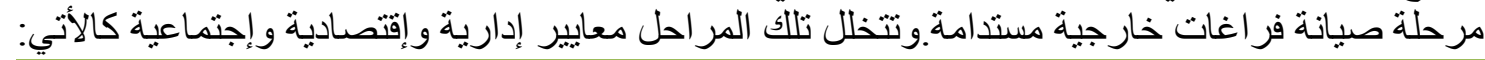

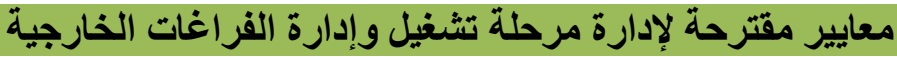

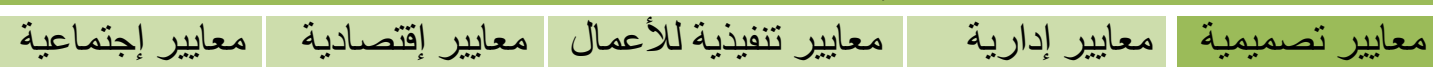

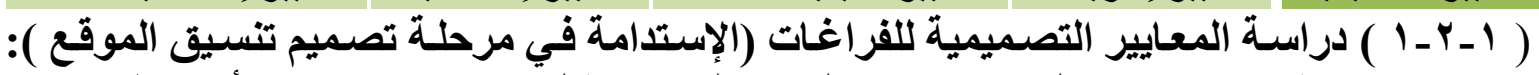

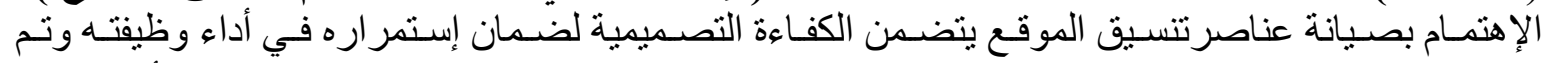

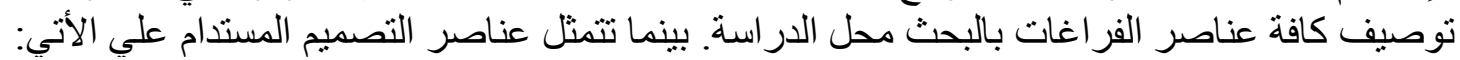

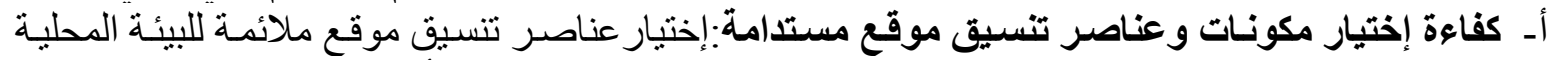

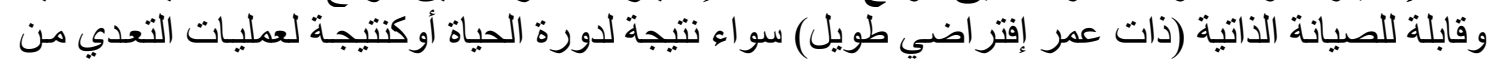

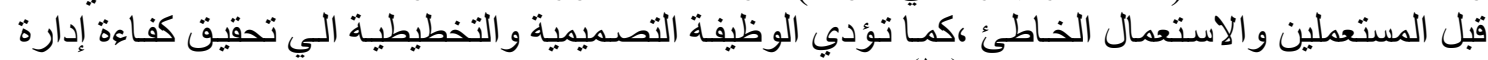

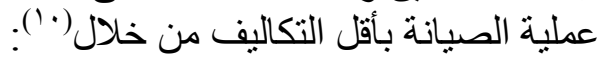

- تحقيق المعايير الوظيفية و التصميمية. - تحقيق ملاءمتها للبيئة المحلية و إستهلاكها للطاقة أو المياه.

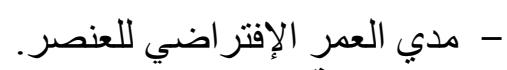

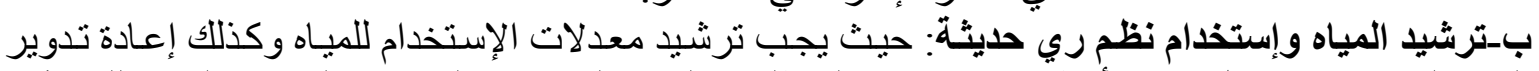

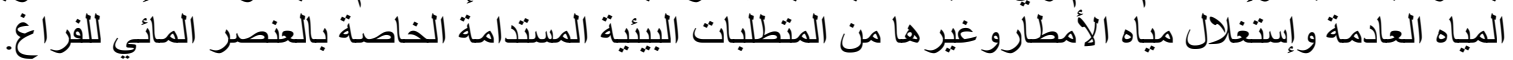

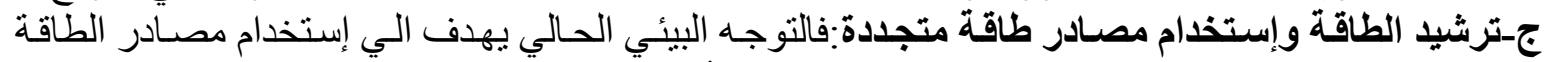

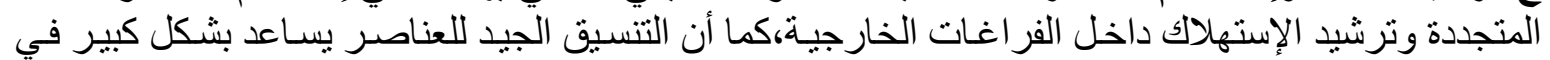

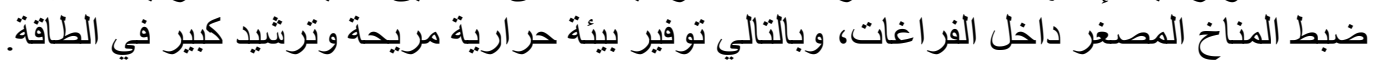

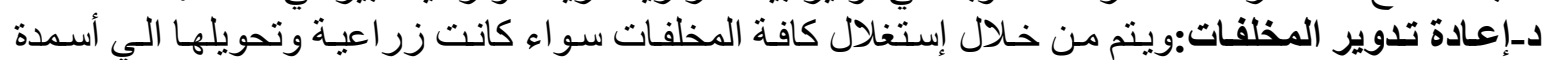

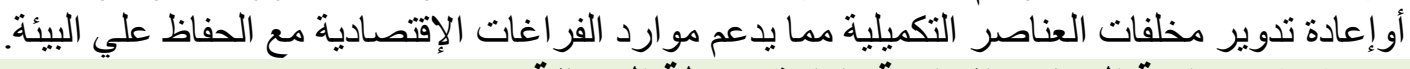

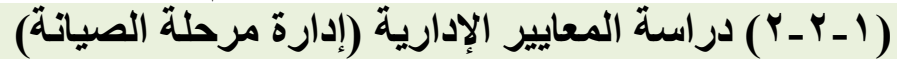

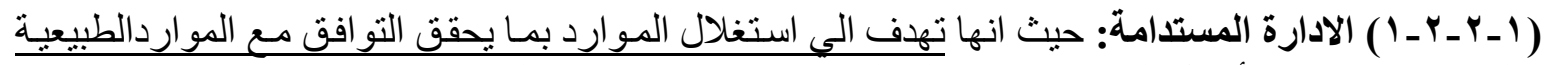

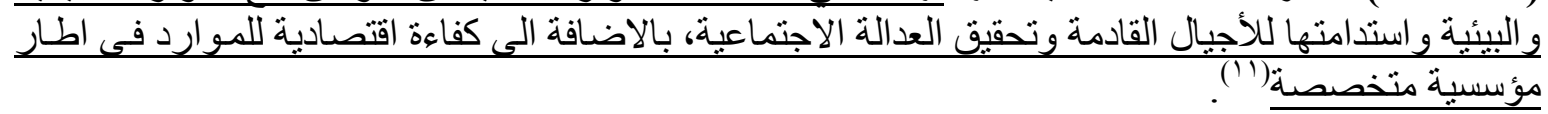

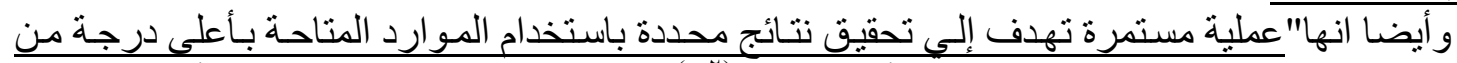

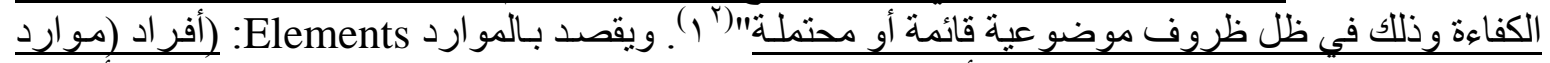

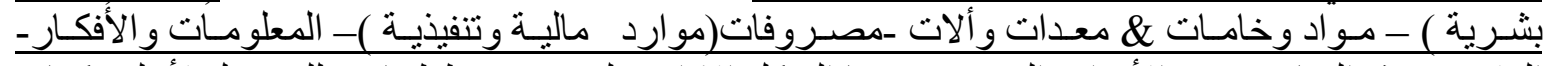

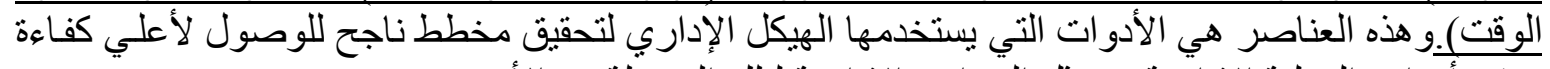

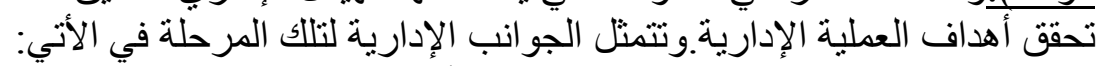

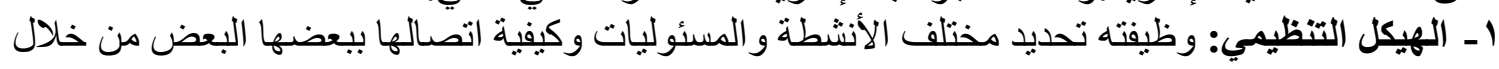
التذرج الوظيفي والتخصص ونو افر فرق العمل و المهارة في الأداءكتوفير الأسس لنظام مكافآت.وفيما يلي لياتي 


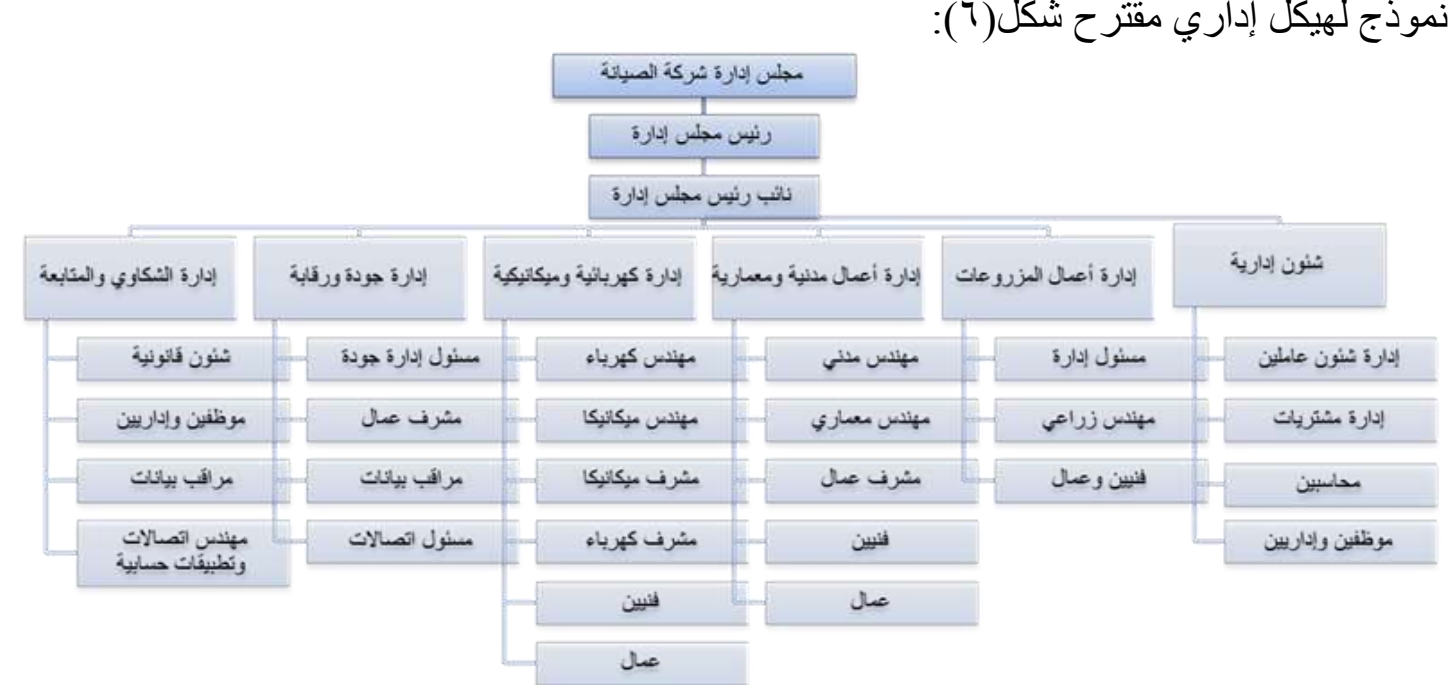

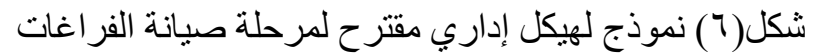

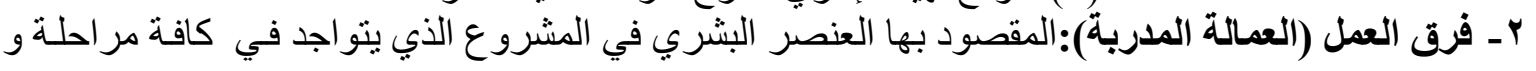

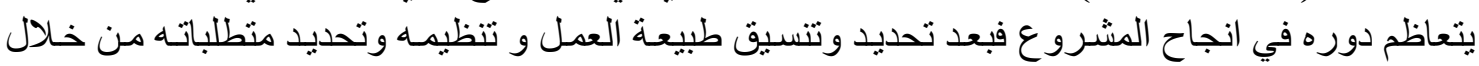

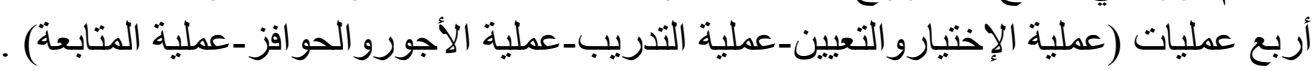

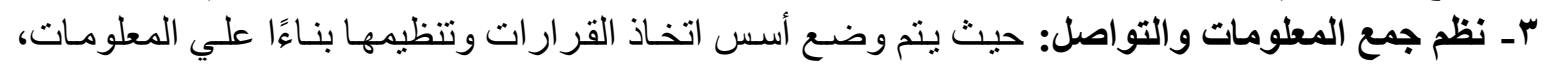

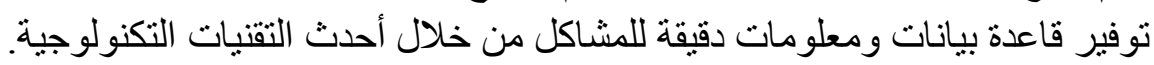

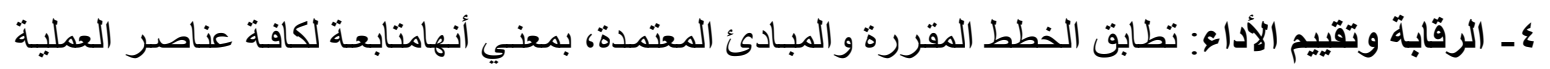

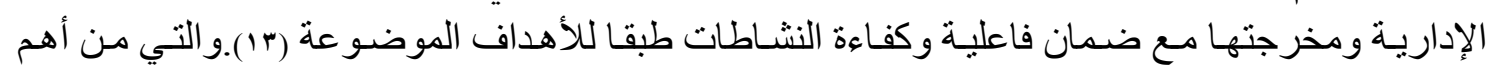

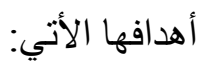

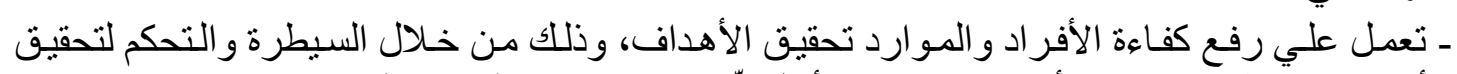

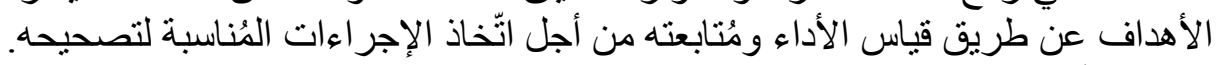

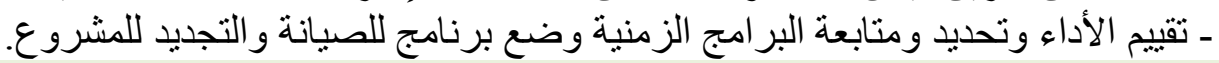

$$
\text { : إدارة الصيانة }
$$

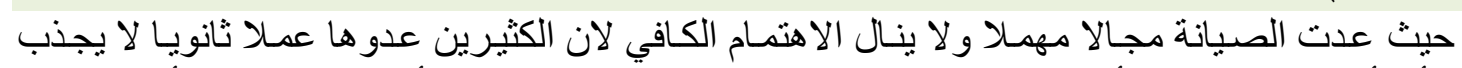

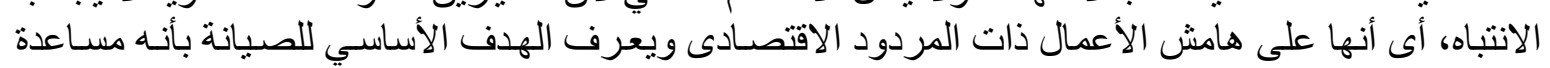

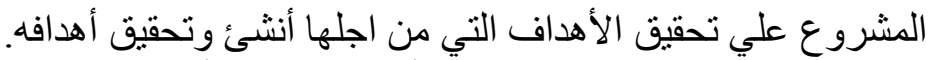

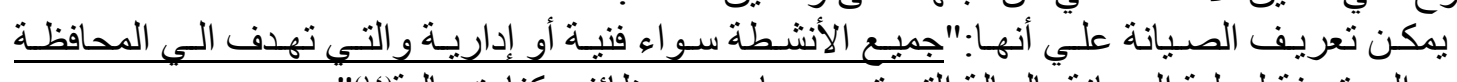

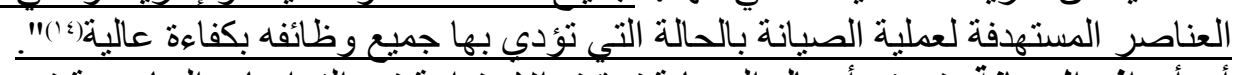

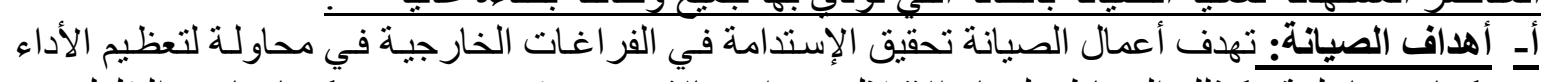

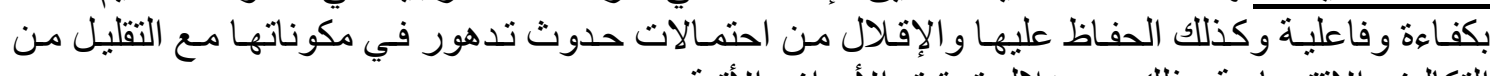

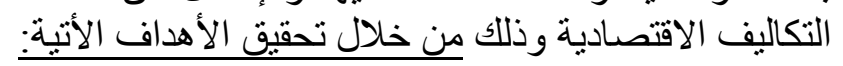

$$
\text { - زيادة العمر الافتر اضي للفراغ. }
$$

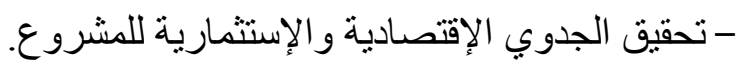
- الحفاظ علي النشطة المستخدمين و البيئة الإجتماعية.

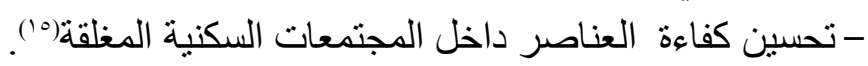

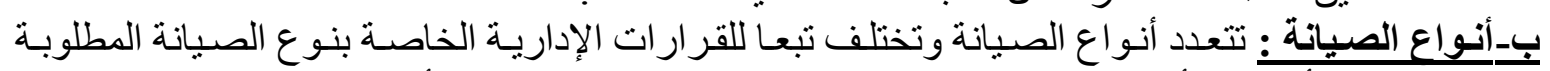

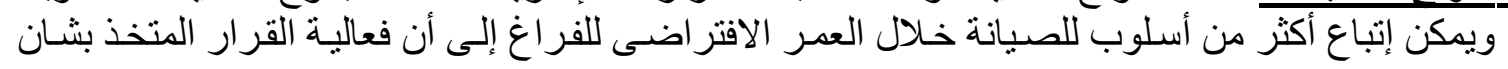


نوع الصيانة ومدى الاستفادة منـه تتوقف على حجم أعمال الصيانة المطلوبـة وأسلوب تتفيذهاوفيما يلي شكل(V) يوضح أنو اع الصيانة.

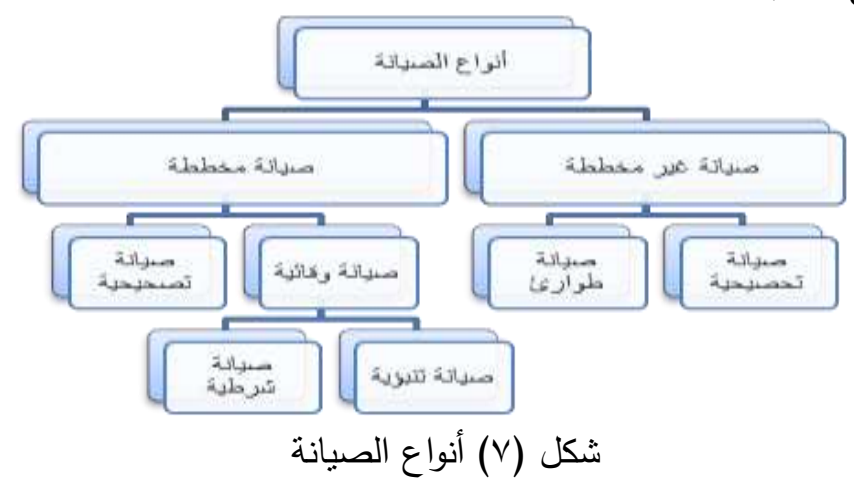

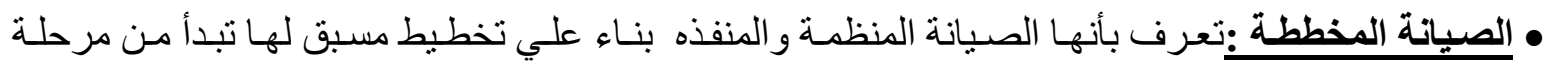

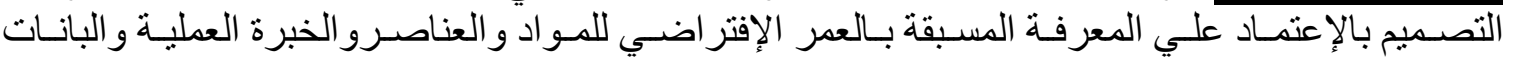

الإحصائية ولهدف محدد مسبقاو الصيانة المخططة الي نو عين هما الصيانة الوقائية و الصيانة التصحيحية.

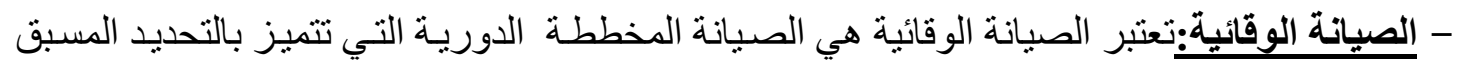

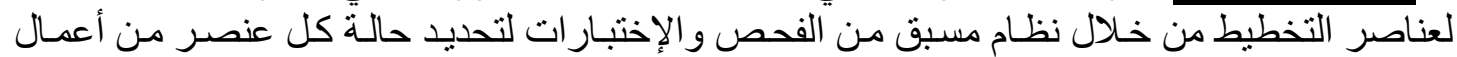

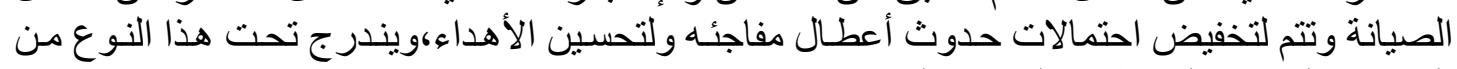

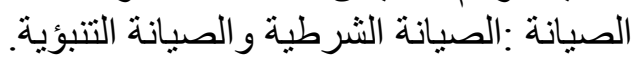

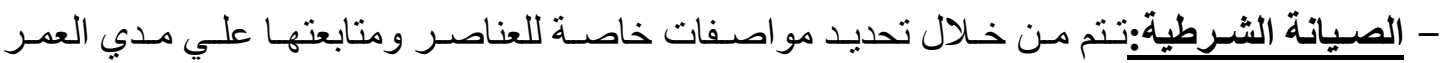

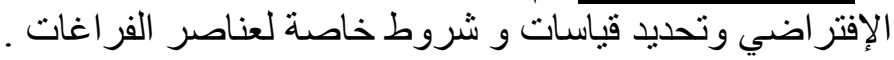

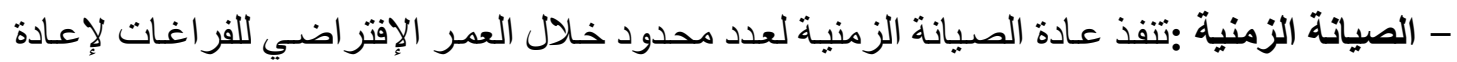

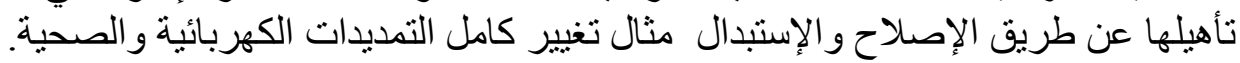

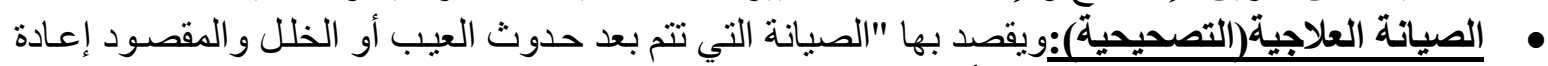

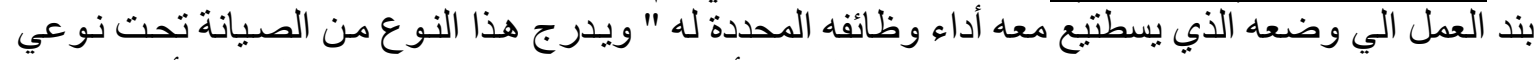

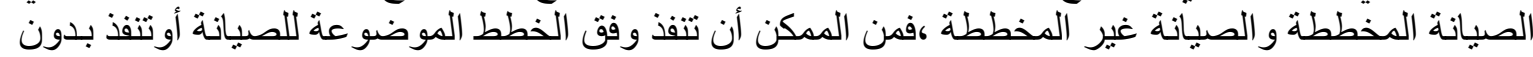

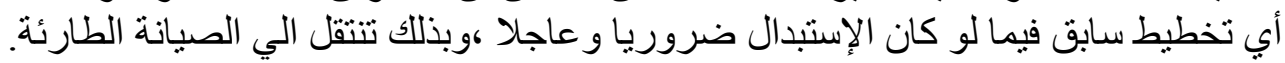

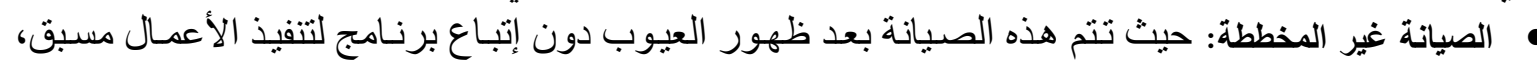

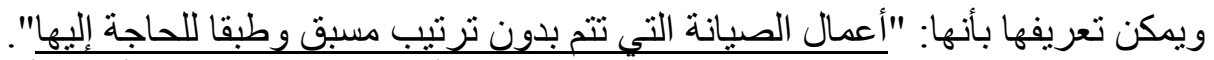

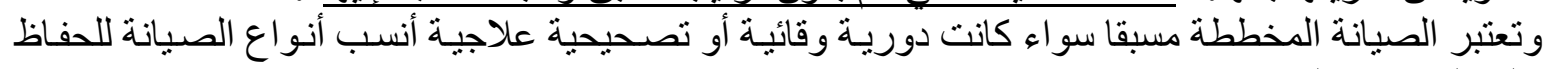
علي الفر اغات الخرجية.

\section{(}

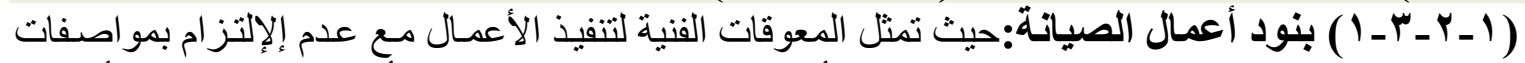

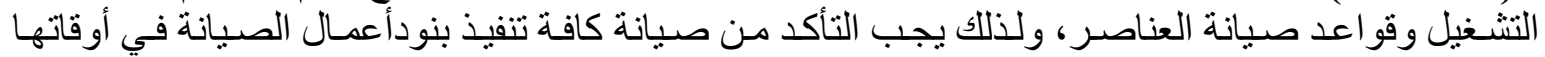

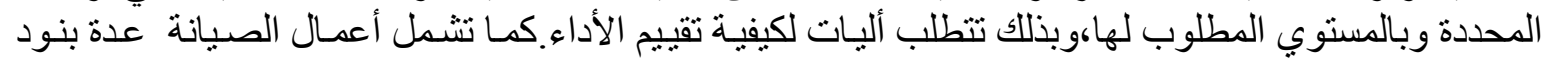

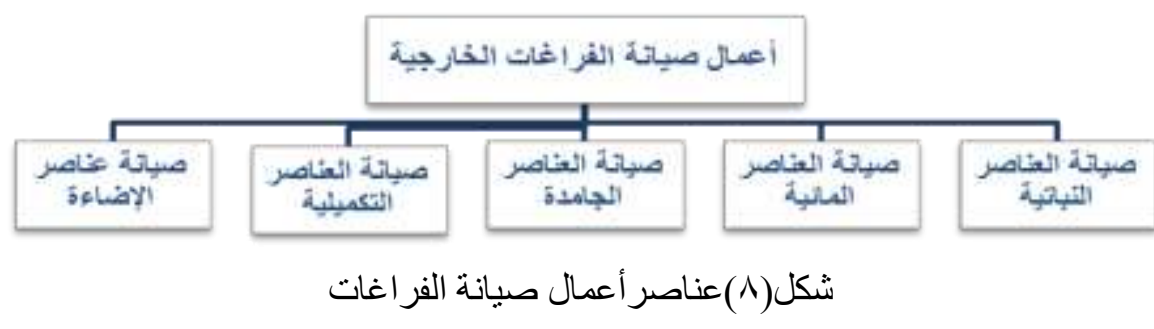


أـ صيانة العناصر النباتية : تبدأ الأعمال من صيانة المزرو عات وتتز امن بـالري والتسميد ومقاومـة الأفات

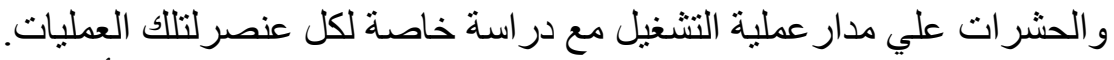
(صيانة العنصر النباتي+الري+التسميد+مكافحة الأفات والحشرة التشرات)

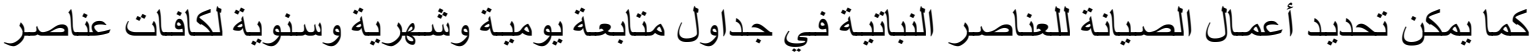

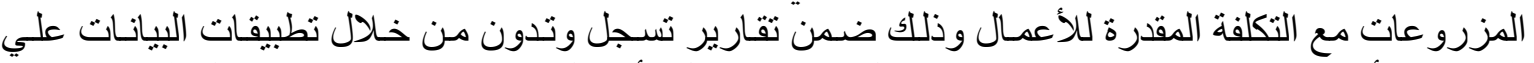

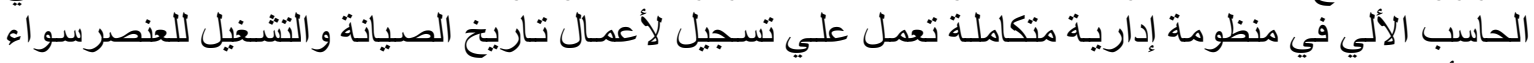

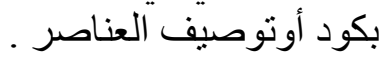
• الري: لكل نوع من أنو اع النباتـات لـه طريقة مخصصـة للري، وفيمـا يلي تحديد لأهم أنواع طرق ري

- النخيل و الأشجار المزرو عة بشكل مفرد: طريقة الري بالببلرز.

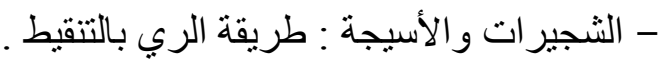
- المسطحات الخضر اء: طريقة الري بالرذاذ.

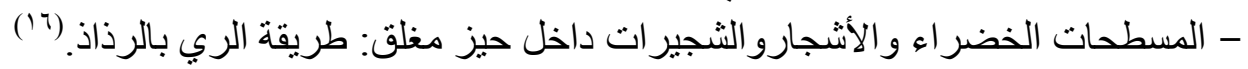

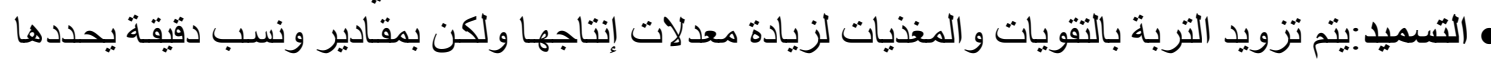

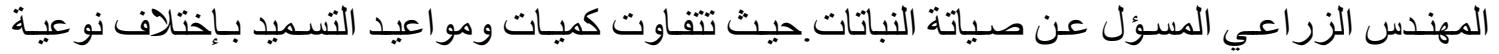
النبات و عمره ـويمكن تحديد الكميات فيما يلي: النيات

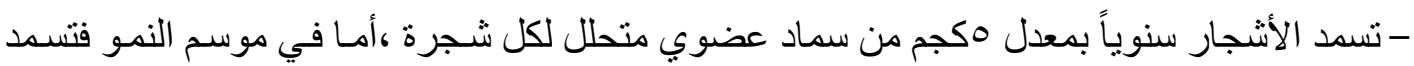

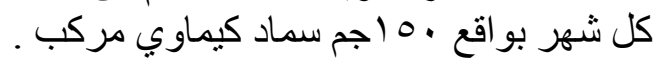

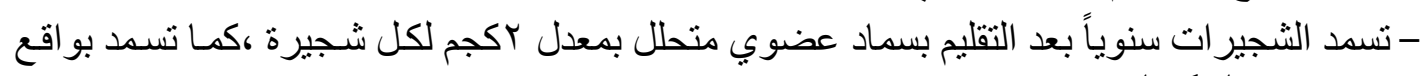

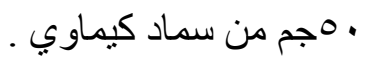

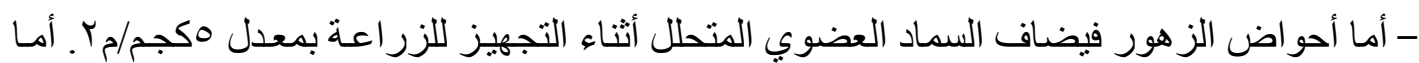

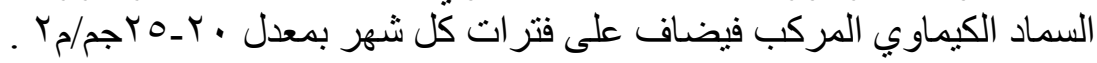

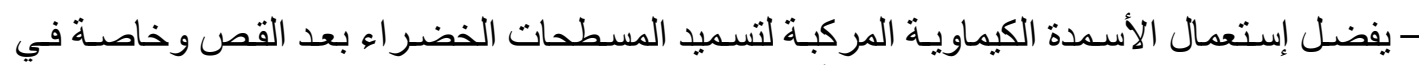

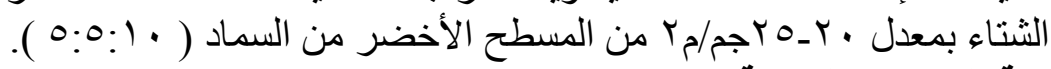

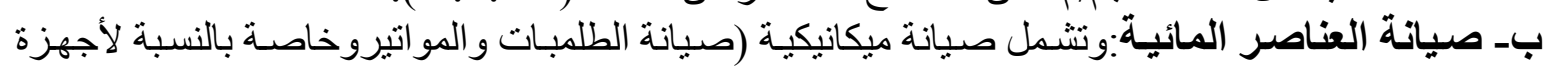

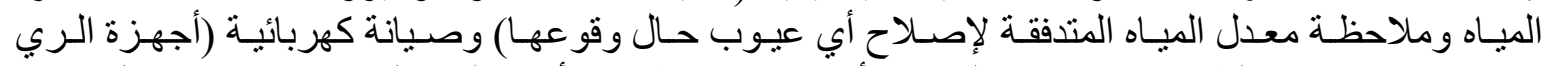

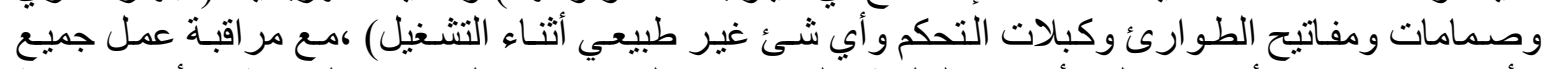

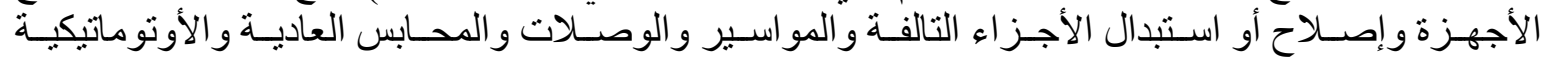

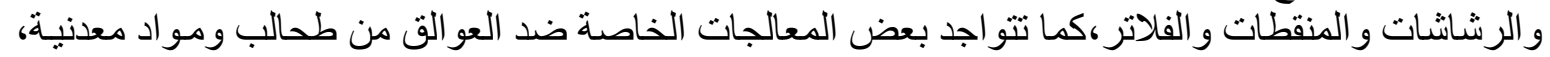

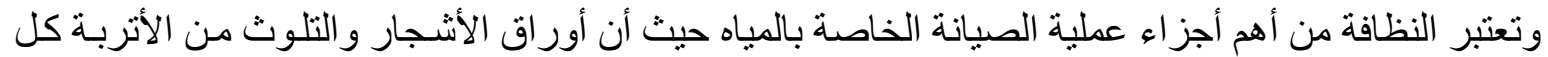

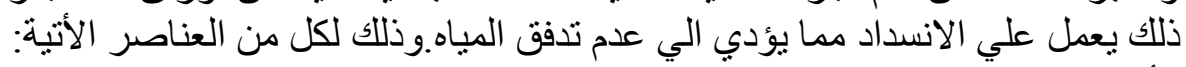

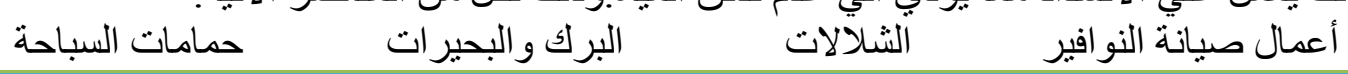

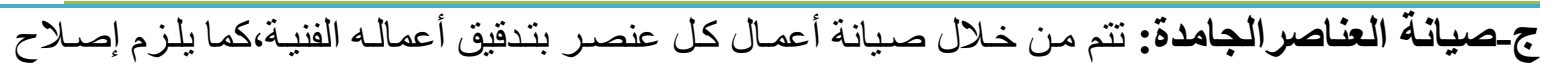

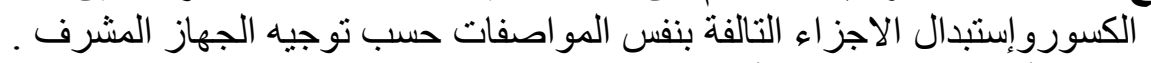

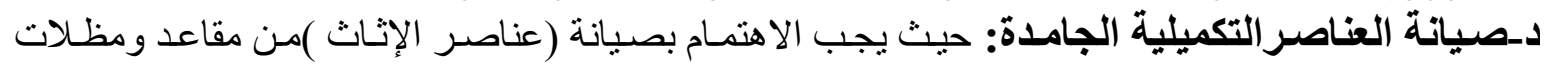

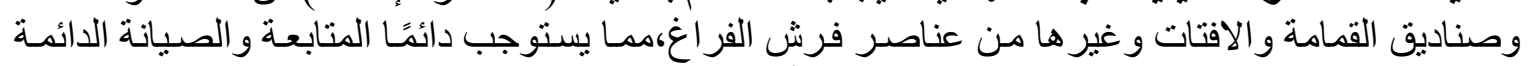

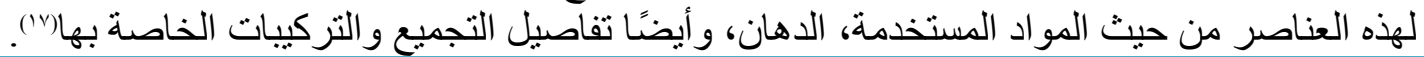

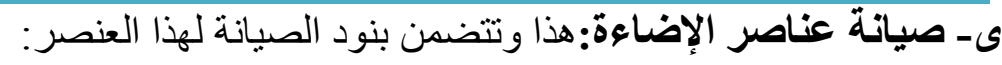

- تغيير الثبكات الازمة في حالة التلف أوالضرة الضرد.

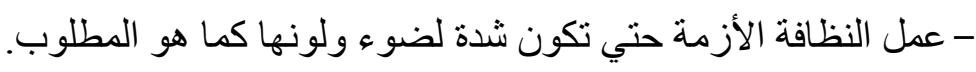

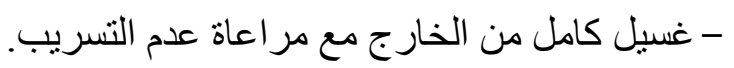




$$
\text { - - إعادة ربط جميع أسلاك اللوحة. }
$$

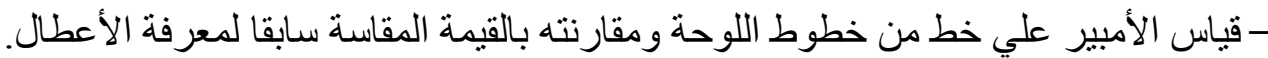
- تدوين القراءات و الملاحظات في جدول الصيانة وتسليمها للمهندس المسئول.

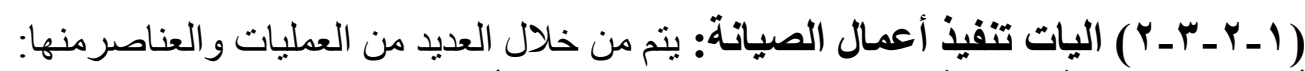

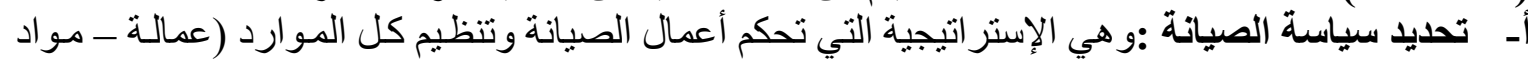

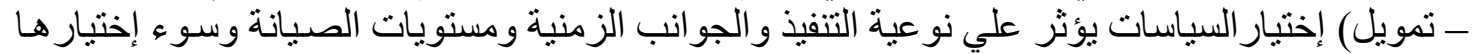

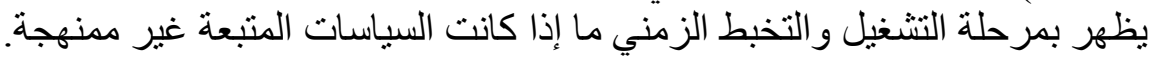

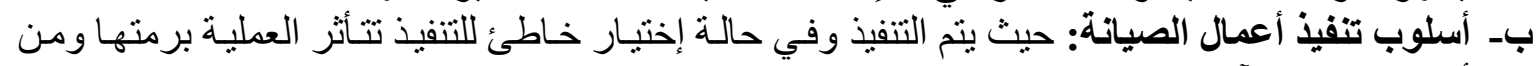

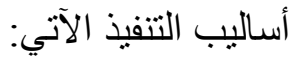

- تنفيذ ذاتي: حيث تتو اجد العمالة بصفة دائمة وتقوم بأعمالها تحت الإدارة وفقا للأعمال المطلوبة.

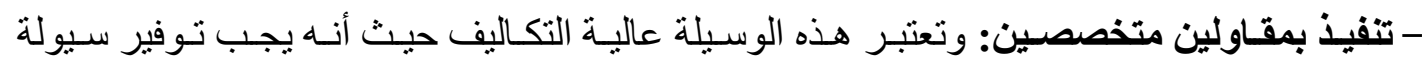

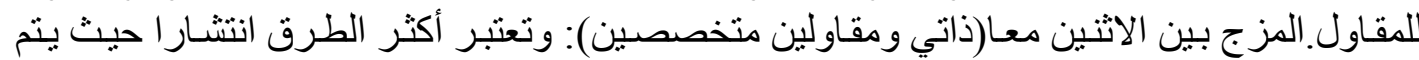

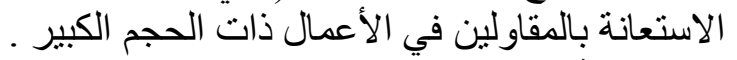

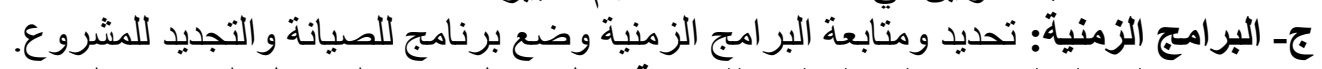

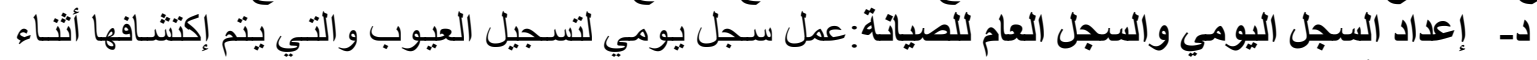

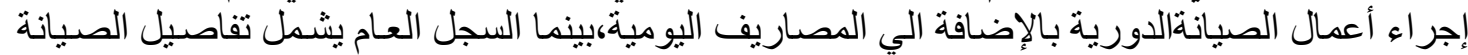

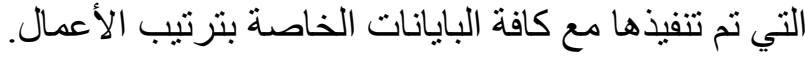

( ) (

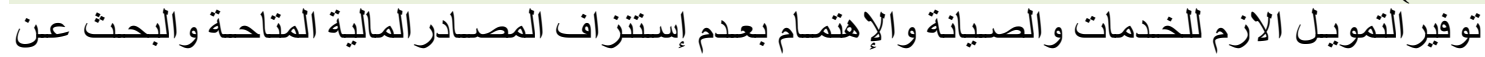

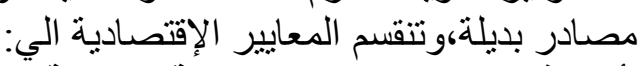

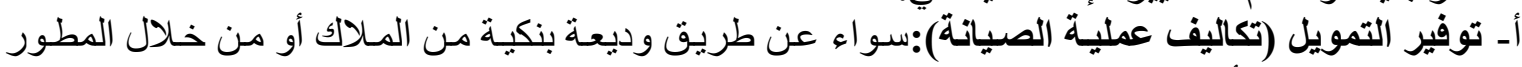

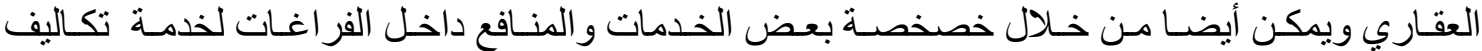
الصيانة. بـ ترشيد وضبط التكاليف: من خـلال ترشيد الإستهلاك أو توفير بدائل تمويلية من داخل الفر اغـات نفسـها

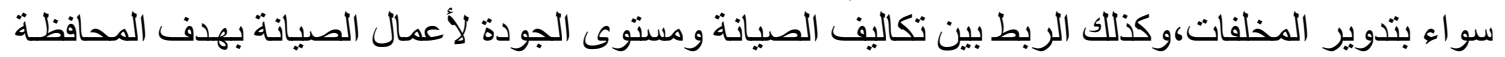

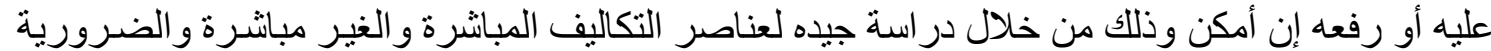

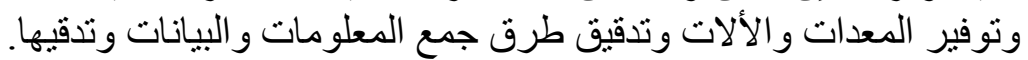

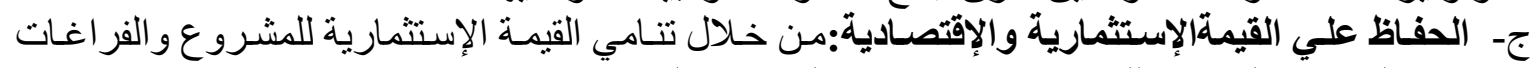

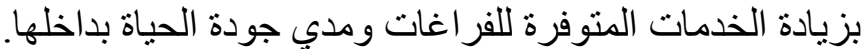

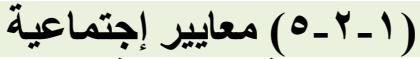

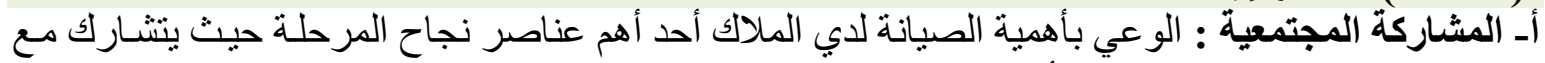

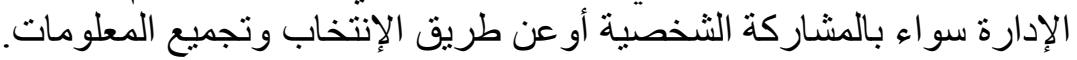

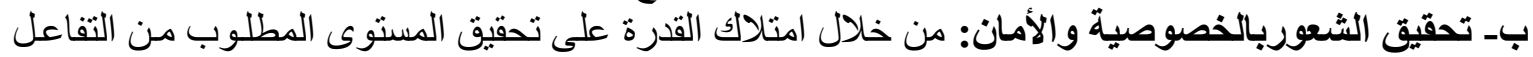

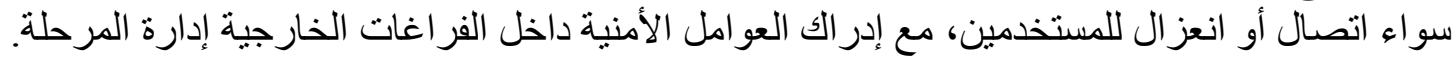

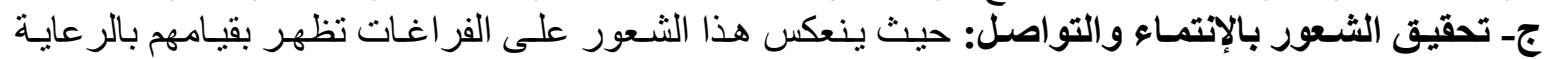

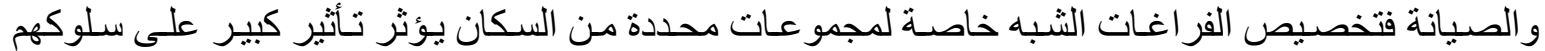
و تفاعلهم معه ،فالإحساس بالانتماء يعد دافع للاهن هنمام و المشاركة . 


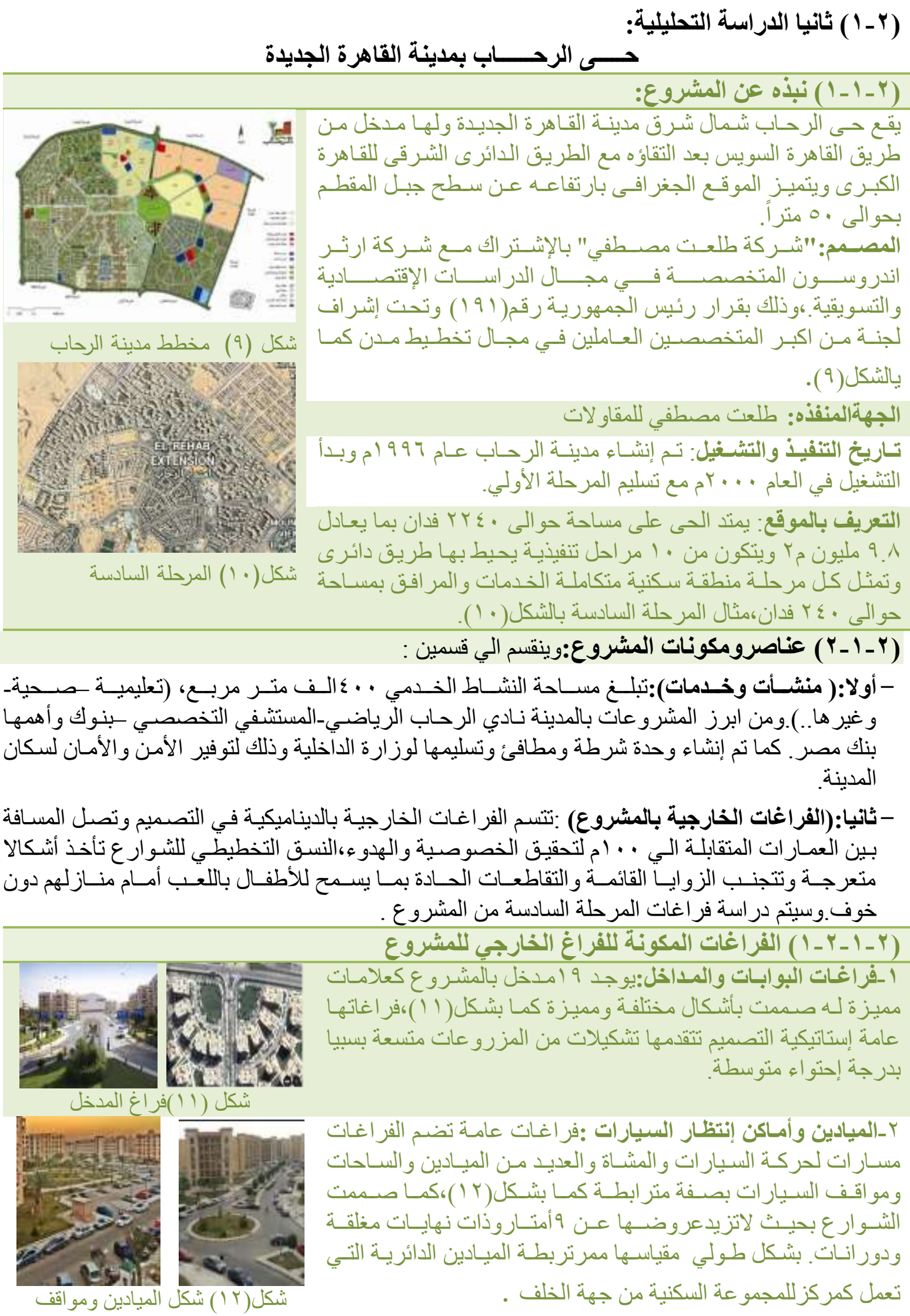



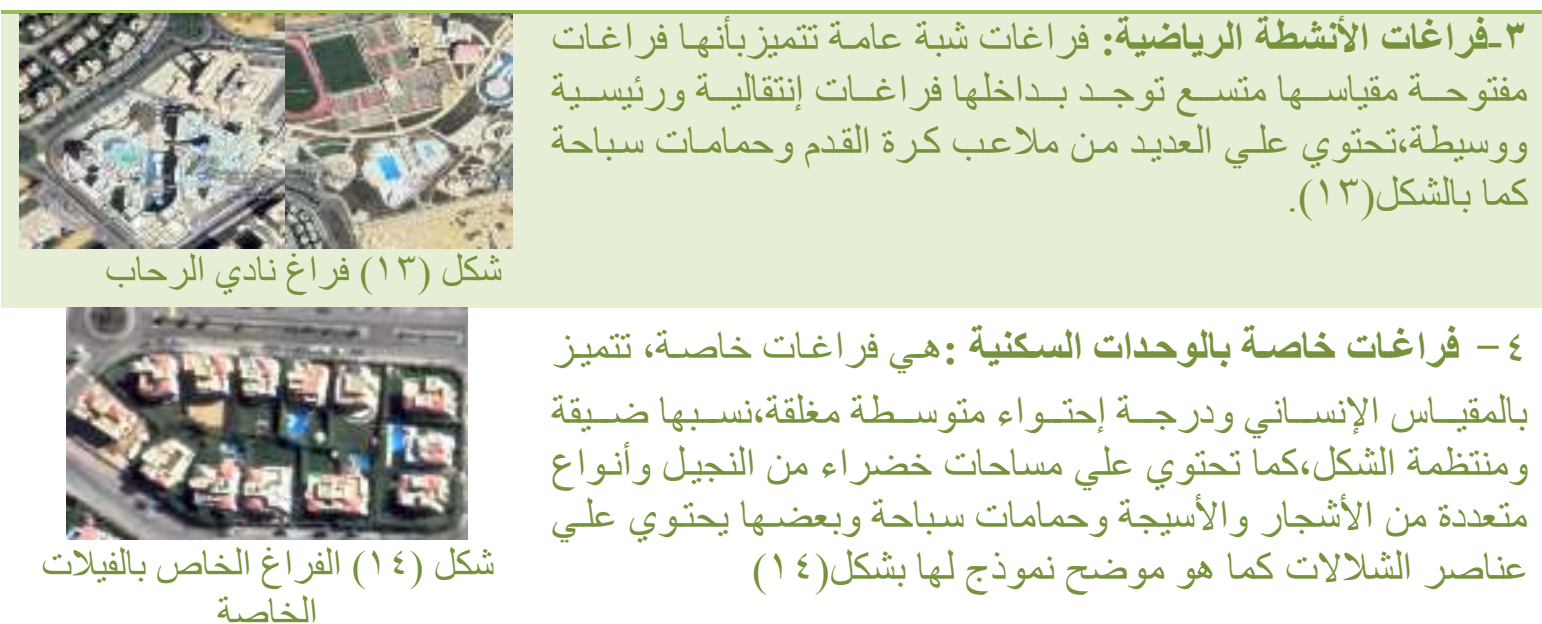

ع - فراغات خاصـة بالوحدات السكنية :هي فر اغات خاصسة، تتميز

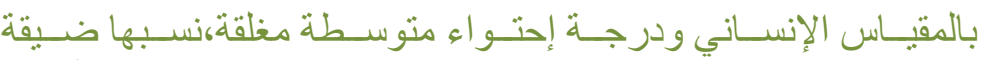

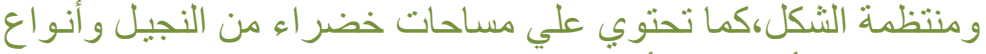

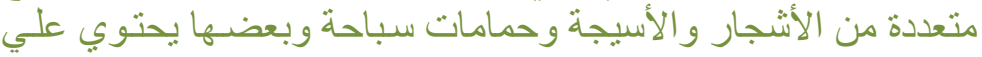

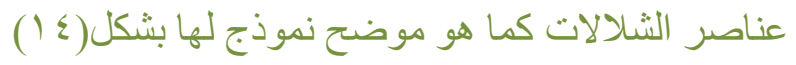

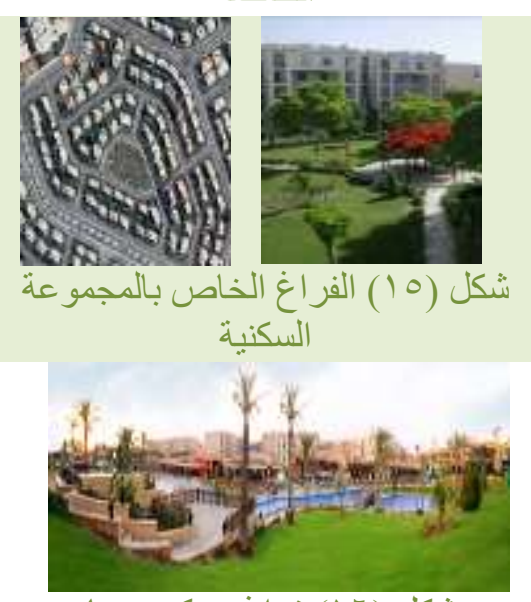

هـفراغ تجميعـي للمجموعـة السـكنية :فر اغـات شـبـه خاصــة تتميـز

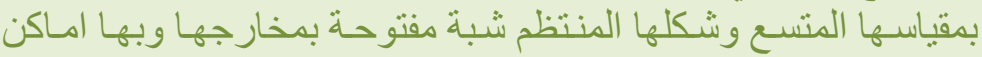

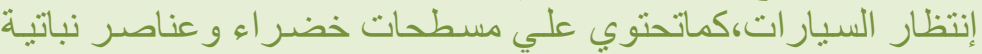

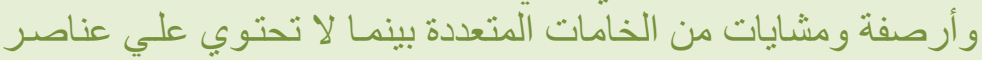
مائية بداخلها هو موضفح بالثكل( 10 ). شُكل (7 ا ) فر اغ مركزي عام

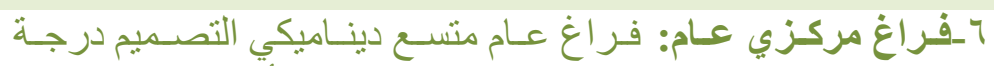

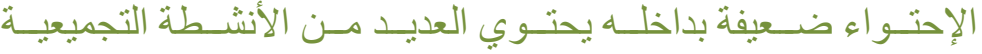

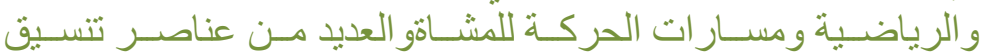

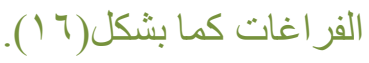

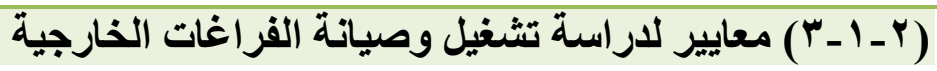

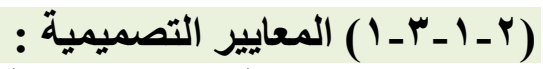
تتم من خـلال در اسـة كيفيـة التخطيط لمرحلة الصنة الصيانة بإختيـار مو اد مستـامة داخل الفر اغـات ومدي

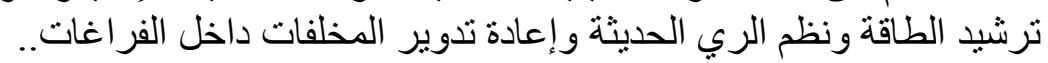

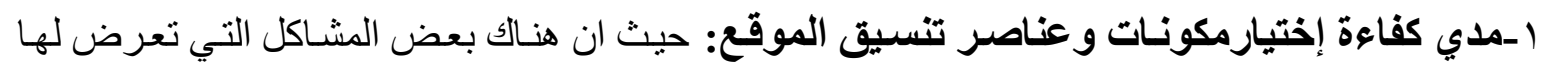

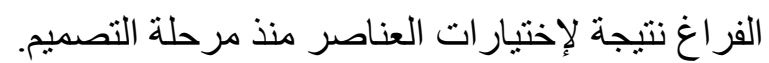

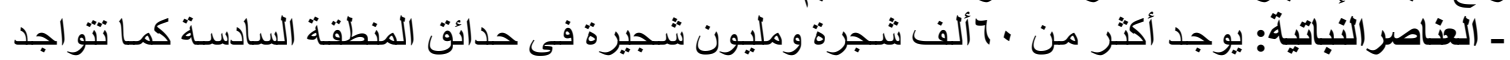

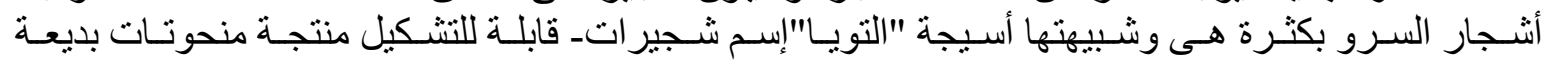

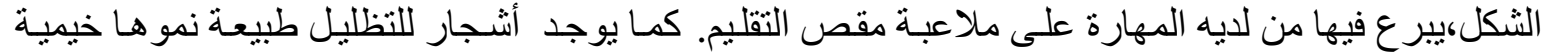

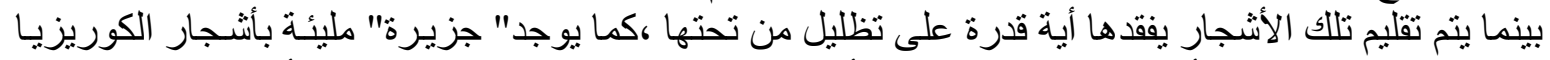

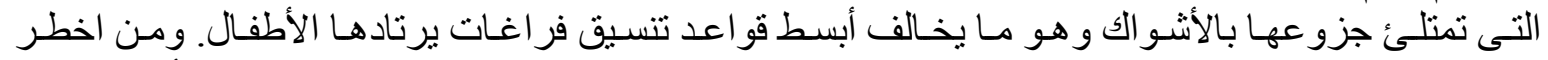

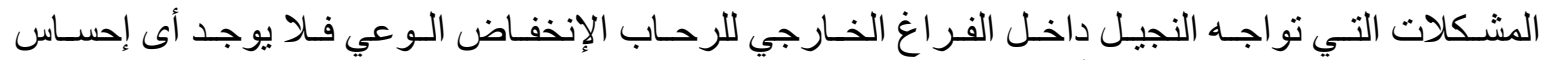

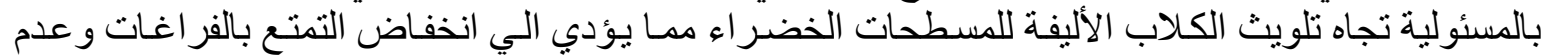

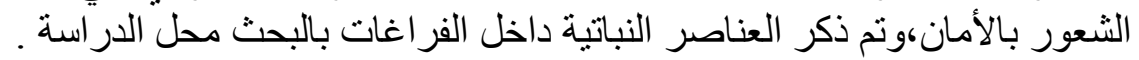

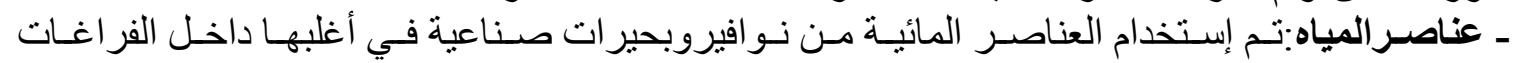

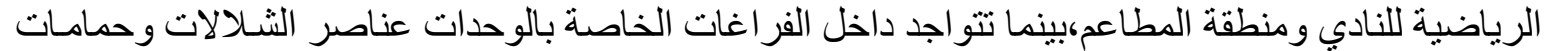




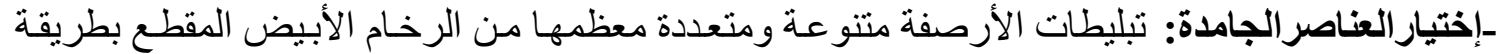

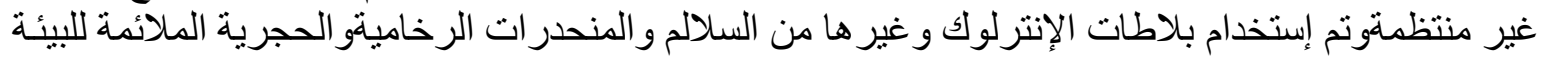

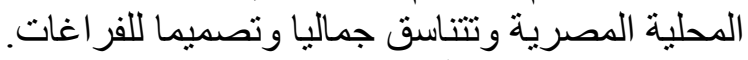

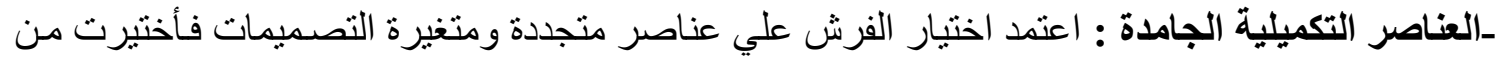

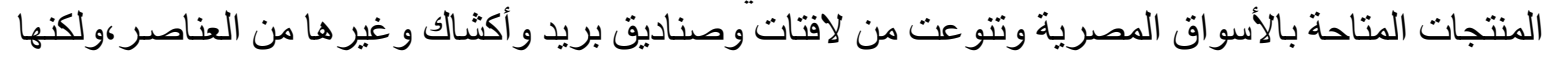

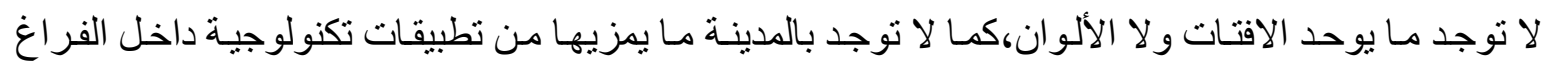

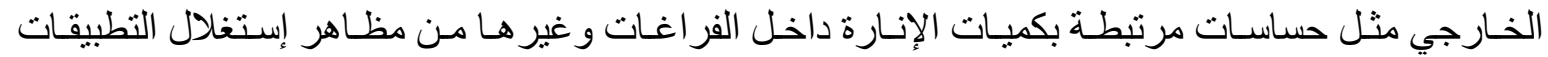

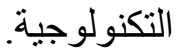

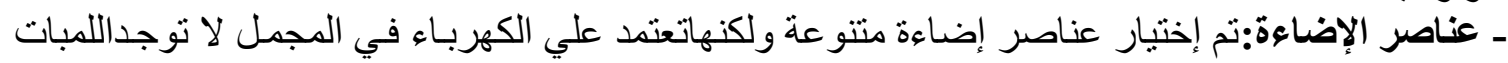

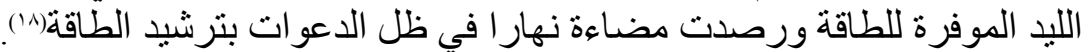

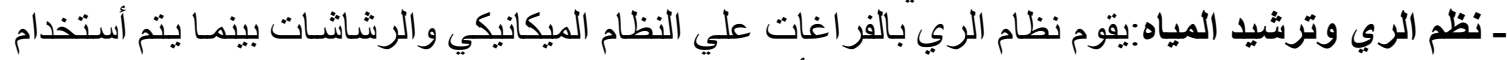

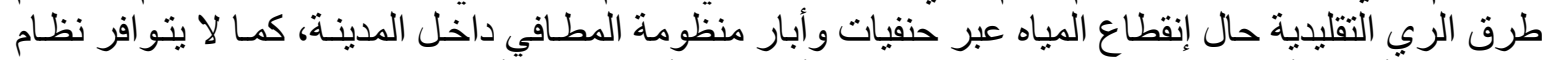

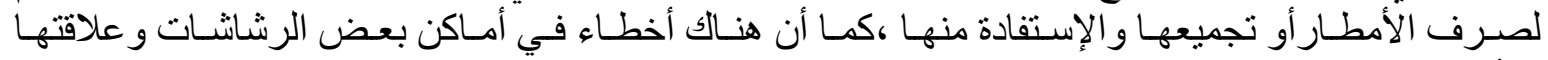
بالأرصفة و التبليطات. ـ ترشيد الطاقة :يتبع جهاز الكهرباء الخاص بالمدينة لهيئة كهربـاء القاهرة الجديدة حيث تعتمد المدينـة علي

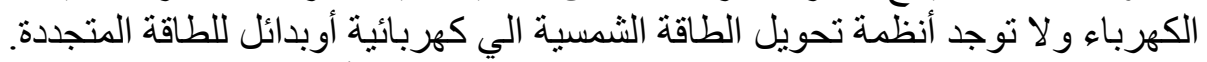

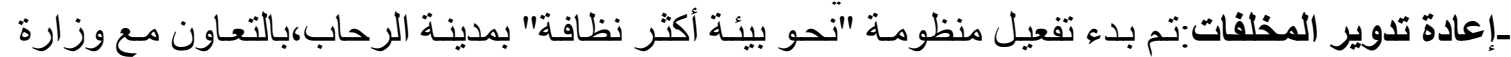

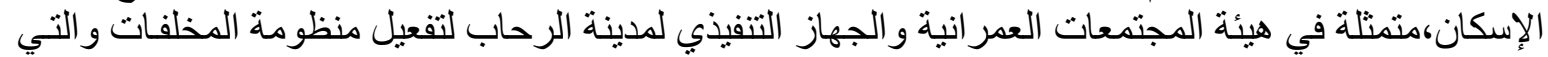

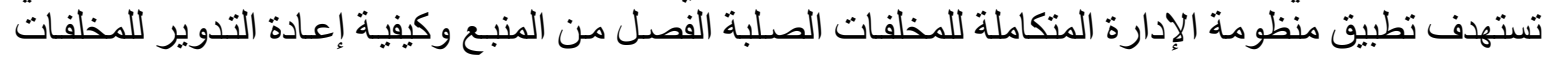

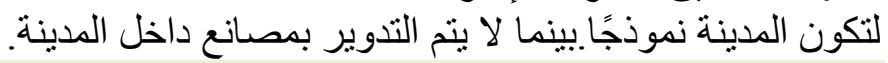

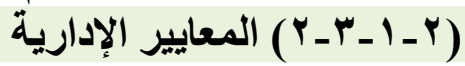

حيث تثمثل المعايير الإداريـة في عدة عناصية الإدر تبدأ بوضـع الأهداف و السياسـات التي يتم تطبيقها من خلال تلاك العناصر : (الت

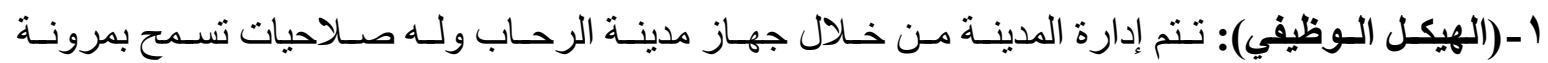

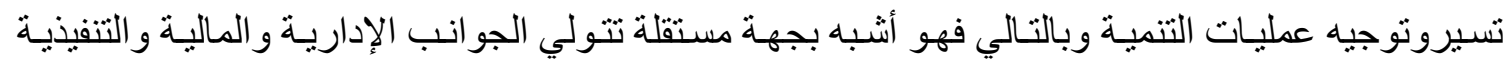

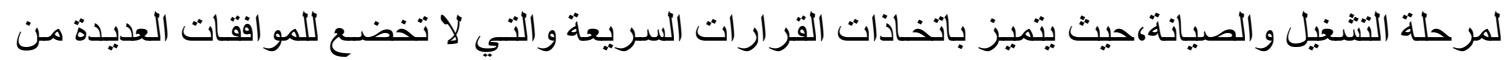

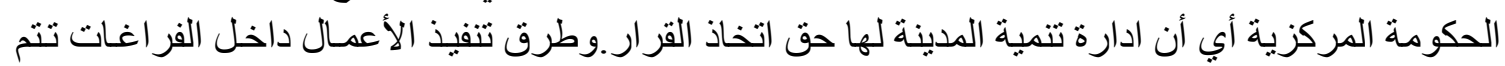

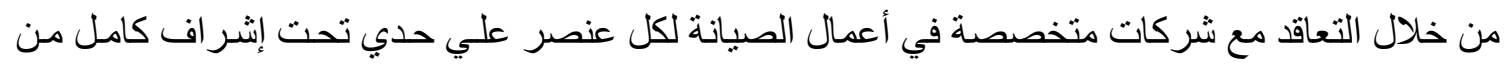
الجهاز ومتابعة للأعمال و العقود.

\section{هيكل جهاز تنمية المدينة: بتشكل جهاز المدينة من:}

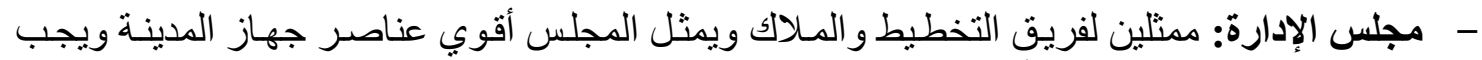

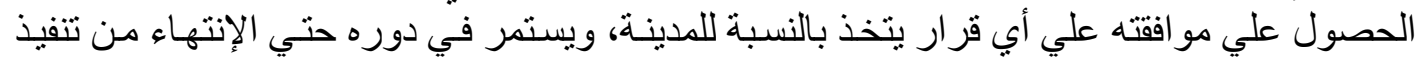

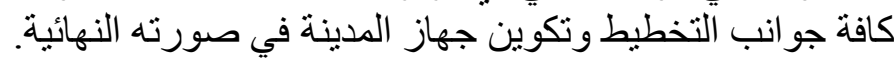

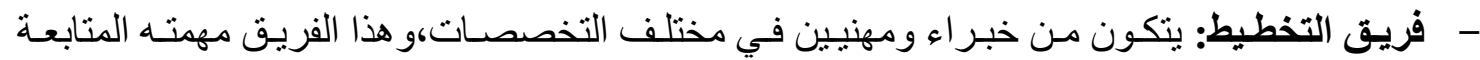

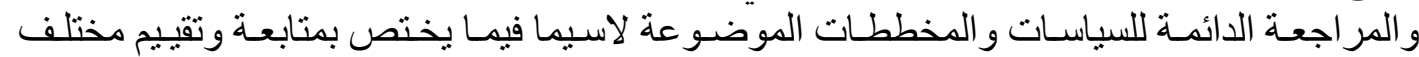

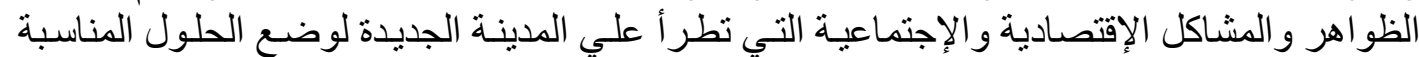

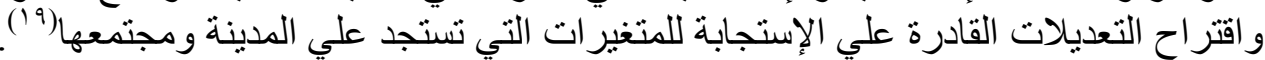

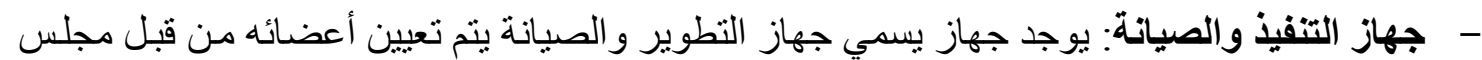

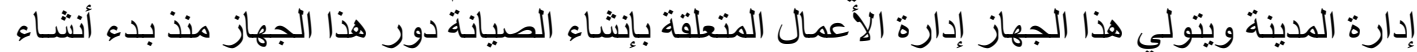

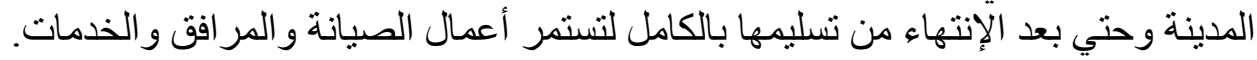




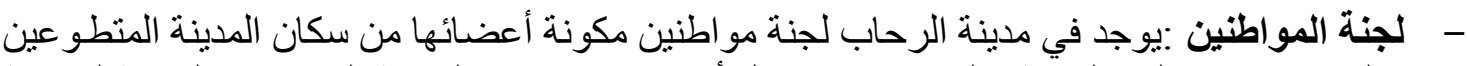

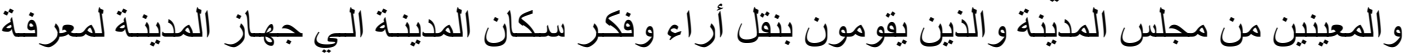

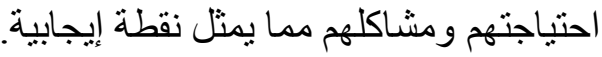

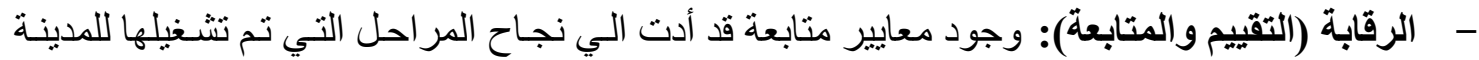

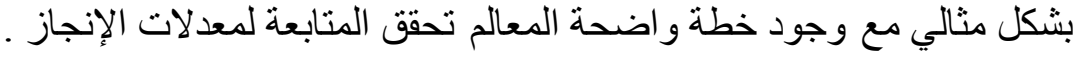

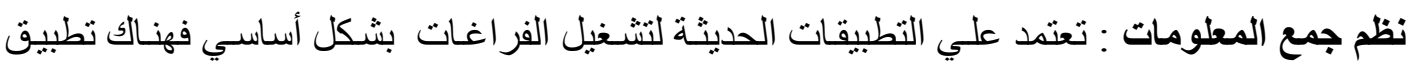

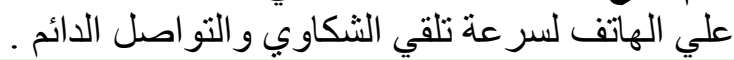

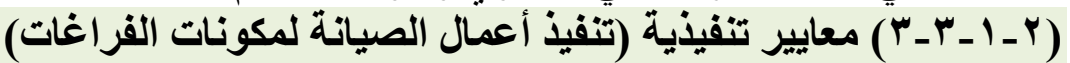

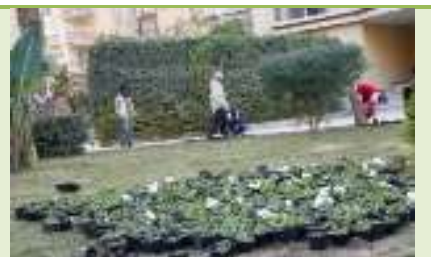

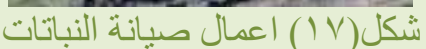

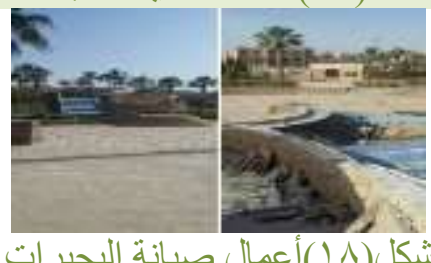

شكل(1) أعمال صيانة البحير ات الصناعية

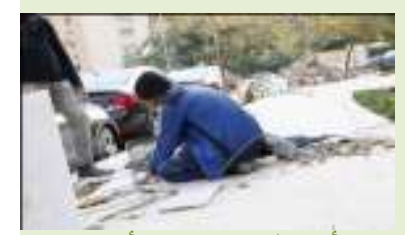

شكل(9 (19) أعمال صيانة الأرصفة

صبانة(العناصر التكميلية(الجامدة): يتم تغيير ودهان عناصر الفرش وصناديق القمامة بصفة مستمرة.

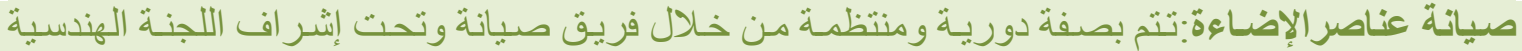
لجهاز المدينة.

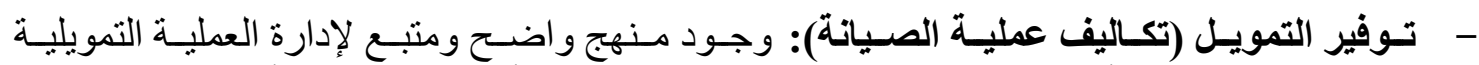

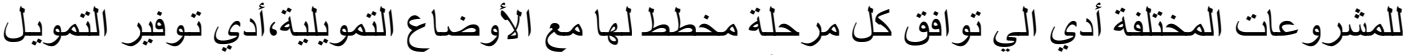

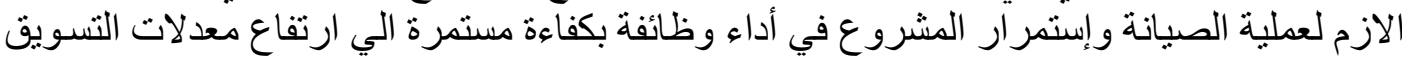
العقاري بالتبعية.

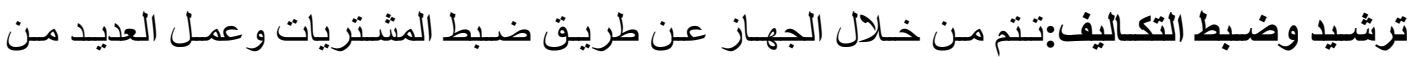

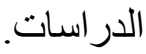

الحفاظ علي القيمة الإستثماريةوالإقتصادية:يلاحظ التطور الإستثماري للمشـروع نيجة لعدم تدهوره

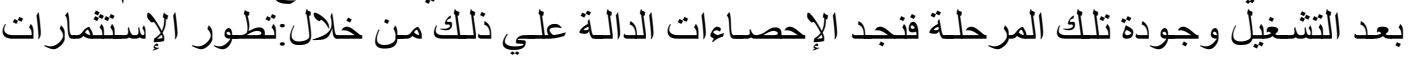

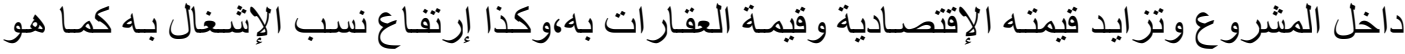

موضح بالثكل (· (Y). 


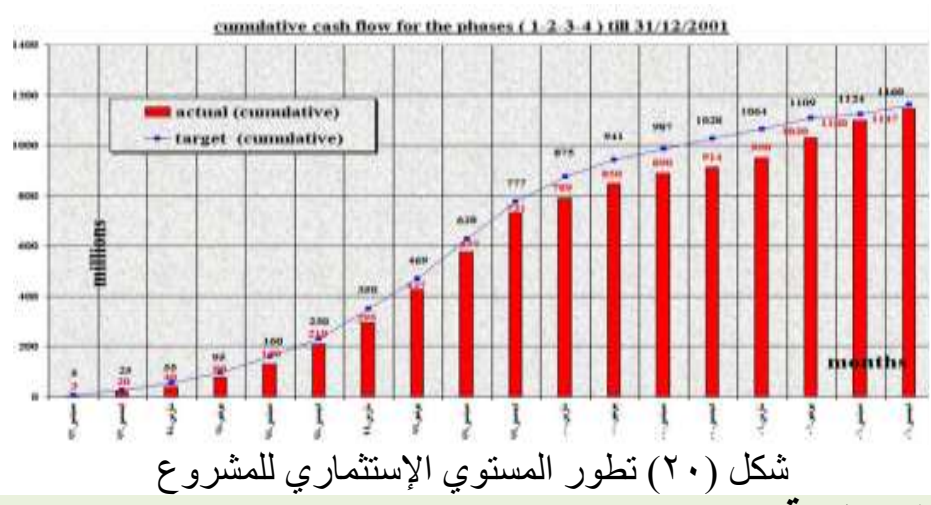

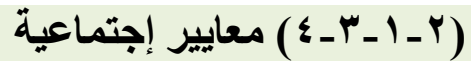

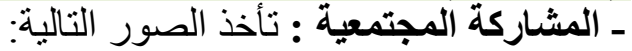

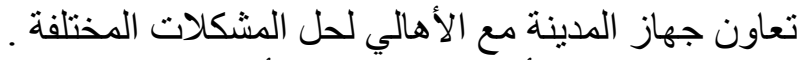

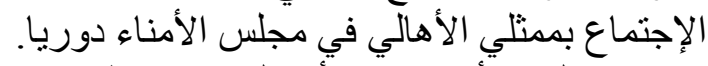

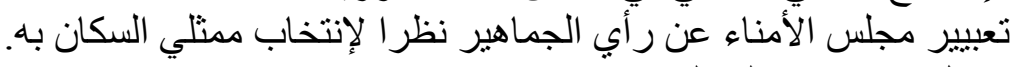

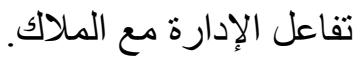

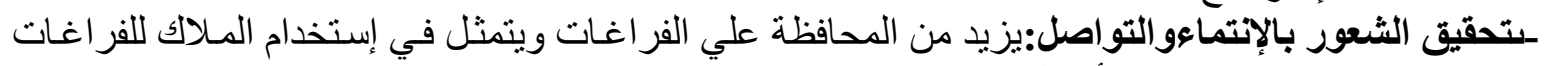

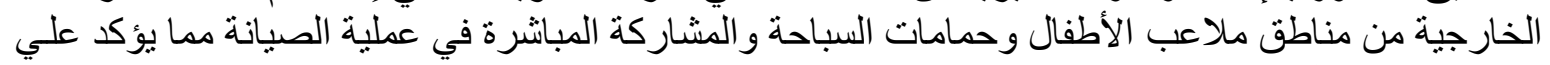

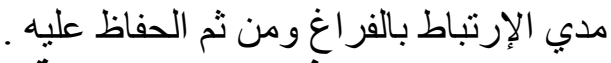

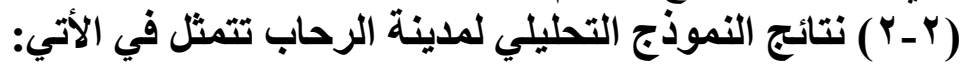

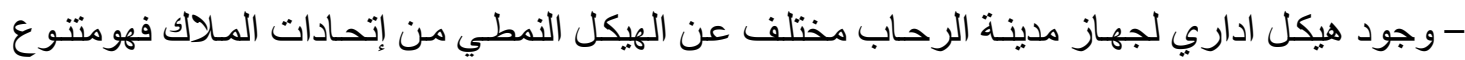

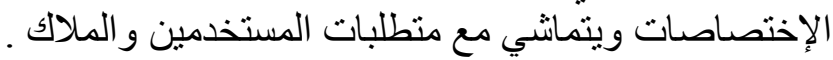

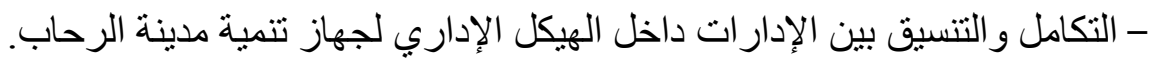
- ترسيخ فكر المشاركة الثعبية في تنمية المدينة.

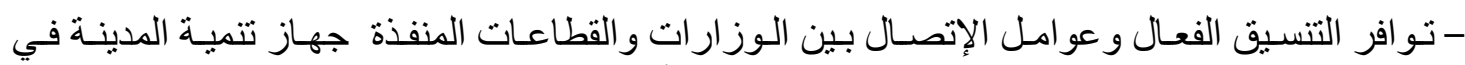

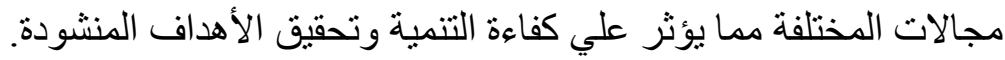

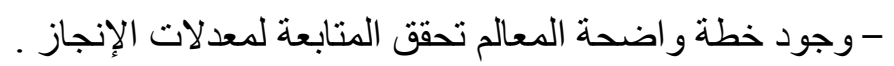

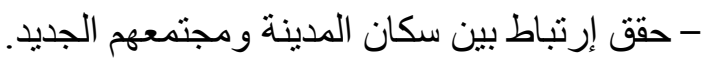

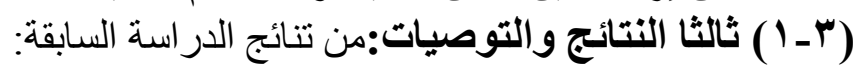

- تأثيرمرحلة التصميم يحدد مستوي مرحلة التشغيل و الصيانة للفر اغات.

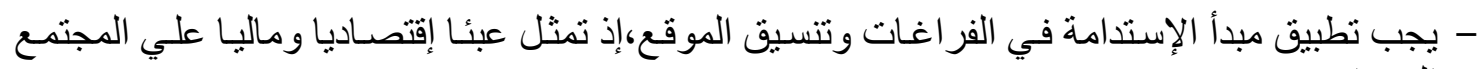
العمر اني.

- إعتماد نظرية إعادة تدوير الموارد و المخلفات:تساعد في توفير التكاليف عوضا عن شر اء مو اد جديدة.

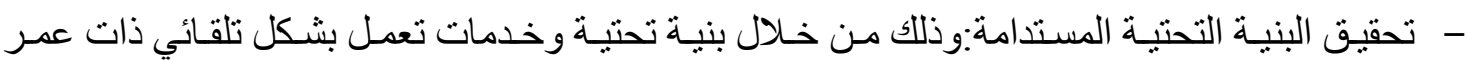
إفتر اضي طويل.

- لابد من التخطبط لعمليات الصيانة و إختبار السياسات المناسبة لتنفيذ الأعمال. - إعتماد مبادئ الصيانة الوقائة.

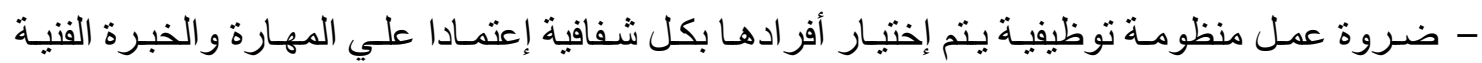
و العلمية وتساعد البيئة المحيطة بتوفير فرص عمل لسكانها.

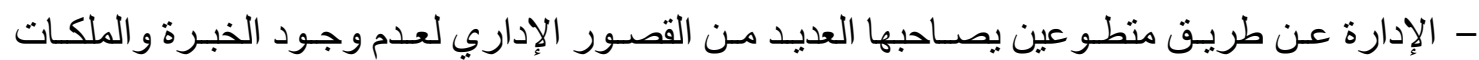

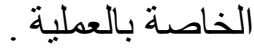




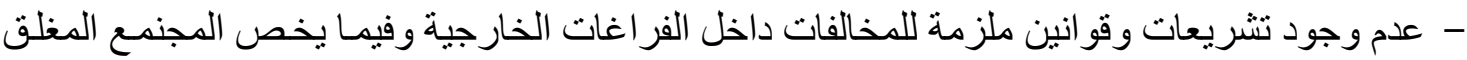
يؤدي الي العديد من التعديات و الإهمال و عدم إكترات المّند المستخدمين.

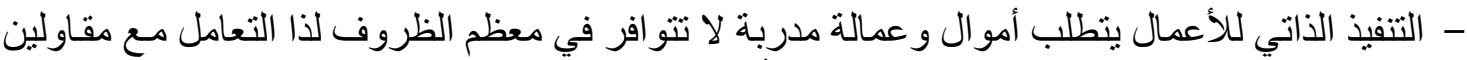

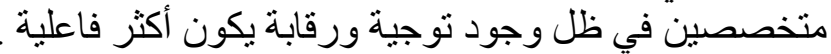

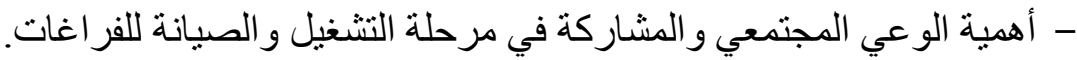

- إختيـار الخامـات الملائمـة للفر اغـات و الموقع خـلال عمليـة التصـيم لإســدامة كفائتهـا وتكلفـة صـيانة منخفضة

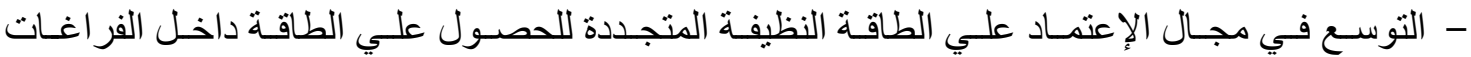
الخارجية.

- ضـرورة صياغة قو انين و إثـتر اطات بنائية تنظم العملية التصميمية وتوفر طـابع معدماري و عمر اني يحقق التكامل بين الخصائص الطبيعية ومعايير التصميم والتخطيط المستدام. - إدر اج نظم فصل المخلفات و إدارة عملية جمع المخلفات بشكل أكثر كفاءة لجعل مهام نقلها سـهل و وإعـادة تدوير وتفعيل النظم الحديثة. - ضرورة توفير التمويل الكافي لأعمال الصيانة المختلفة لعناصـر الفر اغات الخارجيـة كافة حتي يمكن المحافظة عليها بصورة دائمة.

- - إدارة الصيانة تتطلب فريق عمل متكامل ومتخصص يتكون من مهندسين وحرفيين علي كفاءة عالية.

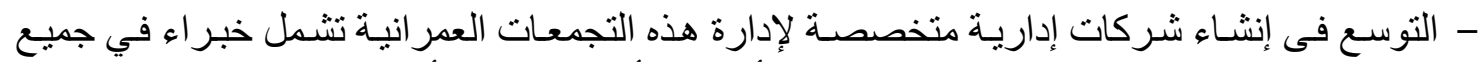

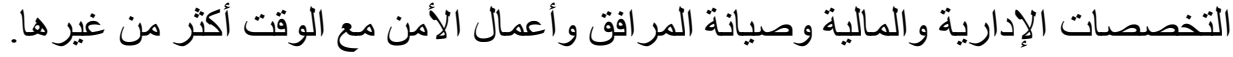

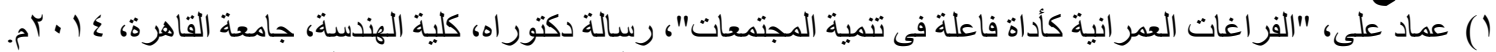

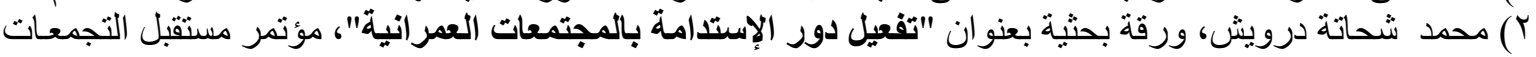

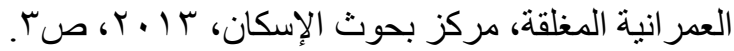

3) Webster B "Gated communities of tomorrow" in Town Planning (2019), pp 149 ع) محمد شحاتهـر اندا جلال، ورقة بحثية، "تفعيل دور الإستدامة للمجتمعات السكنية الخاصة"، كلية تخطيط عمر اني،

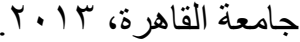

5) http://www.academia.edu/1025407/The_contrbution_of_gated_communities_to_urban_ development_in_Egypt (accessed:12.00pm, 1-8-2019)

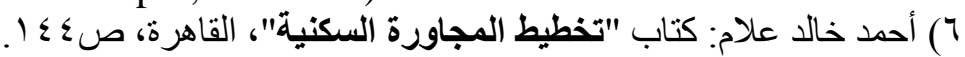

7) http://amenagementa.blogspot.com/2017/02/design-and-planning-of-residentialneighborhoods.html(/(Accessed8:50pm ،18-3-2019)

^) عمرو معتصم،"منهج علمي لتقييم كفاعة تصميم الفراغات الخارجية في القري السياحية"،رسـالة دكتور اة،كلية

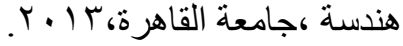
9) جهاز التنسيق الحضاري، الدليل الإرشادي الر ابع و أسس ومعايير التنسيق الحضاري للمناطق المفتوحة و المسطحات

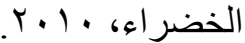

• ( ) أسامة قنبر، "استدامة المنـاطق السكنية بالمجتمعـات الحضـرية الجديدة" رسـالة دكتور اه ـ كليـة الهندسـة -جامعة الأزهر،

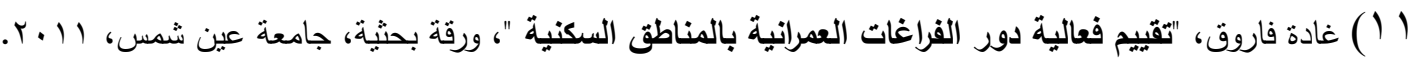
http://www.smgov.net/Departments/OSE/Categories/Landscape/Garden- ( I r Accessed(:15-3-2017)(Garden.aspx س ا)شمس محمود، "نحو إستخلاص النسق العمراني الأوفق للمجتمعات العمرانية الميسرة لذوي الـخل المتوسط"،

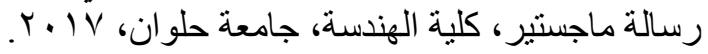


ـ ا) تامر محمد: "توفيق آليات صيانة المباني كأداة للحفـاظ علي الثروة العقاريـة"، رسـالة ماجستير ، كلية الهندسـة،

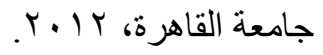

Accessesd:21-2-2019) (https://www.managementstudyguide.com/management_process.htm (10 7 ( ) ريهام عثمان:"منهج لتقييم مشروعات تنسيق الموقع باستخدام مدخلات هندسة القيمة وتكاليف دورة الحياة"، رسالة دكتوراه، كلية الهنسة، جامعة القاهرة، ؟ أ.r.

17) http://www.alrehabcityhall.com/ar/News.

1 1) مجمو عة القاهرة للتخطيط و العمارة،"المخطط العام لمدينة إمتداد الرحاب"، الثركة العربية للمشرو عات والتطوير العمر اني، 2019. 